\title{
Geçmişten Günümüze Zanaat ve Zanaat Mekânları: Trabzon Kenti Örneği*
}

\section{Craft and Craft Spaces from the Past to the Present: Example of Trabzon City}

\author{
Nurçin Seymen Aksu* ${ }^{* *}$, Yelda Aydın Türk ${ }^{* * *}$ (1)
}

\section{Öz}

Dünya'da küreselleşme sürecinin getirdiği mekânsal, sosyal, ekonomik ve kültürel açıdan birçok etkileşim meydana gelmiştir. Bu durum yerel koşulları ön plana çıkararak kentler arasında kimlik ve kültürleriyle anılabilecekleri bir rekabet ortamı yaratmıştır. Kentteki, kültürel yaşam biçimlerini ön plana çıkaran önemli faktörlerden biri de zanaat ve zanaat mekânlarıdır. Zanaat ve zanaat mekânlarının sürdürülebilirliği kent kimliği için büyük önem taşımaktadır. Fakat günümüzde yeni tüketim alışkanlıklarının yaygınlaşması ve teknolojiyle birlikte değişen yaşam koşulları gün geçtikçe zanaat ve zanaat mekânlarının kaybolmasına neden olmaktadır.

Çalışma alanı olarak seçilen Trabzon kenti ticaret ve zanaat bağlamında köklü bir geçmişe sahiptir. Anadolu'nun birçok kentinde olduğu gibi Trabzon kentinde de kentleşmeyle birlikte günümüzde zanaat ve zanaat mekânları geçmişteki önemini yitirmiştir. Ancak kentte geleneksel biçimde üretim yapan bazı zanaat türleri özellikle tarihî kent merkezi başta olmak üzere hâlen varlığını sürdürmektedir.

Bu çalışmada; önemli ticaret ve zanaat geçmişine sahip olan Trabzon kentinde tarihî süreç içinde zanaat ve zanaat mekânlarının dönüşümünü hem mekânsal hem de zanaatkârların görüşleri doğrultusunda sosyal açıdan irdelemek, bu mekânların canlandırılması, korunması ve sürdürülmesine yönelik öneriler geliştirmek amaçlanmaktadır. Çalışmada ilgili konuya yönelik literatür araştırması, zanaat mekânlarına yönelik yerinde tespit ve gözlem ve günümüz zanaat mekânlarına yönelik fotoğraflama çalışmaları ve zanaatkârlarla görüşmeler yapılmıştır. Elde edilen bilgilerle haritalar ve sayısal veriler oluşturularak tarihî süreç içerisinde zanaat ve zanaat mekânlarının değişimi ortaya konulmuştur.

Anahtar Kelimeler

Kent, Kent Kimliği, Kent Kültürü, Zanaat, Zanaat Mekânları, Trabzon

\section{Abstract}

There are many spatial, social, economic, and cultural interactions brought about by the globalization process across the world. This situation brought local conditions into the forefront. Thus, the competition of identity and culture among cities came into view. One of the important factors that emphasize cultural lifestyles in the city is that of craft and craft spaces.

* Bu makale Karadeniz Teknik Üniversitesi, Fen Bilimleri Enstitüsü, Şehir ve Bölge Ana Bilim Dalı́nda Doç. Dr. Yelda Aydın Türk'ün danışmanlığında 2018 yılında Nurçin Seymen tarafindan hazırlanan "Geçmişten Günümüze Zanaat ve Zanaat Mekanlarının Değişimi: Trabzon Kenti Örneği" başıklı yüksek lisans tez çalışmasından üretilmiştir.

** Sorumlu Yazar: Nurçin Seymen Aksu (Öğr. Gör.), Bartın Üniversitesi, Ulus Meslek Yüksekokulu, Mimarlık ve Şehir Planlama Bölümü. Bartın, Türkiye. E-posta: nsaksu@bartin.edu.tr ORCID: 0000-0002-0787-0661

*** Yelda Aydın Türk (Doç.Dr.), Karadeniz Teknik Üniversitesi, Mimarlık Fakültesi, Şehir ve Bölge Planlama Bölümü. Trabzon, Türkiye. E-posta: yelda@ktu.edu.tr ORCID: 0000-0002-1281-7478

Atıf: Seymen Aksu, Nurcin ve Aydin Turk, Yelda. “Geçmişten Günümüze Zanaat ve Zanaat Mekânları: Trabzon Kenti Örneği." Art-Sanat, 15(2021): 317-345. https://doi.org/10.26650/artsanat.2021.15.0013 
Sustainability of craft and craft spaces is of great importance for urban identity. However, the widespread use of new consumption habits and living conditions which accompany developing technology are causing the loss of craft and craft spaces on a daily basis.

The city of Trabzon, the study area of the present study, has a long history in terms of trade and crafts. As in many cities of Anatolia, with the urbanization in Trabzon, today, craft and craft spaces have lost their importance they had in the past. However, some types of crafts that have traditionally been produced in the city still exist, especially in the historical city center.

The city of Trabzon has an important trade and craft background. The aim of this study is to analyze the transformation of crafts and craft spaces socially in terms of both space and the points of view of craftsmen, and to develop suggestions for the revival, protection and maintenance of these spaces.

To this end, the related literature was reviewed, an on-site detection and observations of the craft spaces were made, craft spaces were photographed, and craftsmen were interviewed. Based on the information obtained, maps and numerical data were created and, therefore, the transformation of crafts and craft spaces was revealed.

Keywords

Urban, Urban Identity, Urban Culture, Craft, Craft Spaces, Trabzon

\section{Extended Summary}

Compared to a rural settlement, a settlement that has different urban functions, that generates income from sectors other than agriculture and livestock, and that has such characteristics as trade, housing, administration, education etc. is called a city. The basic functions of cities have experienced change and transformation with urbanization. The effects of these changes and transformations are more prevalent in city centers. The craft spaces that have cultural value and where production and sales are made are generally located in historical city centers. These spaces both lead the work of the craftsman and gain value and meaning with the presence of the craftsman. A craft is a type of production that provides information about the cultural life of the city. In addition, it is a concept that reflects the lifestyles, thoughts and beliefs of societies.

With globalization, one may see that a competitive environment has emerged in which local conditions (such as historical textures, traditional textures, architectural structures, lifestyles in the cities) have come into prominence. In this competitive environment, lifestyles in the city gain value in terms of identity and culture. Craft and craft spaces that have preserved their traditional production styles are also among the important symbols of identity and culture of the city. Craft spaces are areas that can transfer the social, economic and cultural structure of the city from the past to the present. These places can preserve their meaning and vitality with the presence of craftsmen. In historical city centers, craftsmen who do the same craft often coexist and these places are usually named after that craft type. For this reason, keeping craft and craft spaces alive is important for the sustainability of the city's identity and culture.

The city of Trabzon has many identity components in terms of natural, cultural and architectural aspects. It experienced its brightest period when trade was at its peak. It 
has been an important trade center on the Silk Road. As time passed, the importance of trade in the city increased and different types of services started to enter the city. Crafts such as shoemaking, woodworking, weaving, coppersmithing, silversmithing and quilting were very important in the city in the past. Since the trade was intense, the craft spaces in the city are important identity components integrated with the urban culture.

The aim of this study is to examine the transformation of craft and craft spaces in the city of Trabzon, both spatially and socially in line with the views of craftsmen. In the study, the related literature was reviewed, an on-site detection and observations of the craft spaces were made, craft spaces were photographed, and craftsmen were interviewed. First of all, literature research on the city, urbanization, urban identity, urban culture, craft and craft spaces was made and maps, photographs and pictures were analyzed. The current spatial situation of craft and craft spaces was determined. Sharia records, travelogues, yearbooks, maps, photos, pictures, theses and books on the topic were analyzed, and craftsmen and related people were interviewed. Then, in order to find out about the current work-related problems of the craftsmen, an interview was prepared and the craftsmen were interviewed. The data obtained from the field study about the past and present were shown in maps. Thus, the spatial change and transformation of craft spaces in the city was revealed.

The data obtained from the fieldwork and interview have shown that the types of craft have gradually decreased quantitatively and changed spatially. Crafts such as shoemaking, coppersmithing, quilting and tailoring can be defined as crafts that have survived up to the present day with a decreasing number; crafts such as jewelry, filigree and silkmaking can be defined as crafts that adapted to the technological, economic and socio-cultural conditions and improved; and crafts such as pottery, crate making, basketry, leatherwork and broomwork can be defined as crafts which have not been able to keep up with the ever developing technology and which have been unable to survive as a result of mass production techniques. The names of different parts of the city is an indicator that shows that a craft is still alive: Potter, Cratemaker Street, Tailors' Street, Tailors' Plaza, Saddlers' Street, Shoemakers' Street, and Coppersmiths' Bazaar.

Finally, planning studies should be carried out in order to protect, revitalize and sustain craft spaces by determining the problems and potentials of the area. It should be supported by developing craft-oriented urban policies with the cooperation of Public institutions, private investors, non-governmental organizations (NGOs) and the community itself. The city and urbanites must be brought together by creating craft-oriented cultural spaces where exhibition, research and educational activities can be organized in streets and squares that have an important role in creating urban space and craft identity. These spaces to be created will help ensure the sustainability of craft spaces. 


\section{Giriş}

Küreselleşme süreciyle Dünya'da mekânsal, kültürel, soysal ve ekonomik birçok yönden etkileşimler artmış, bölge ve kent düzeyinde yerel koşulların ön plana çıktığı bir rekabet ortamı oluşmuştur. Bu ortamda kentler artık kimlikleriyle ve kültürleriyle ön plana çıkmakta ve önem kazanmaktadır. Kültürel yaşam biçimlerini öne çıkaran en önemli faktörlerden biri de kentteki zanaat ve zanaat mekânlarıdır. Bu mekânların yaşatılması kent kimliği ve kent kültürünün sürdürülebilirliği açısından oldukça önemlidir.

Zanaat, toplumların sosyo-kültürel hayatları hakkında bilgi edinmeyi sağlayan bir üretim türüdür. Zanaat tarzı üretim yapan atölyelerin küçük ölçekli olmaları ve el emeğiyle üretim yapmaları, bu üretim tarzını günümüzde popülaritesi yüksek olan endüstriyel üretimden farklı kılar. İnsanların ihtiyaç duydukları nesnelerin üretimini karşılamak için el emeğine, çıraklık-kalfalık-ustalık aşamalarına dayalı bir etkinlik olan zanaat, çeşitli eşyaların üretiminin yanı sıra, bakımı, tamiri vb. dışında hizmet konusunu da kapsamaktadır.

Zanaatkârların mesleklerini gerçekleştirdikleri mekânlar olan atölyeler ya da dükkânlar genellikle zanaat türü ile tanımlanmaktadır (kuyumcu dükkânı, ayakkabıcı vb). Dükkân daha çok zanaatkârın ürünlerini pazarladığı, atölye ise zanaatkârın mesleğini uygulayarak gerçekleştirdiği, tecrübesini çıraklarıyla paylaştı̆̆1 yerdir. Usta-çırak ilişkisinin önemli olduğu bir çalışma ruhu, zanaatkârın bulunduğu mekânı benimsemesi ve yere özgü bir kimlik yaratması gibi olgular zanaatkârın hayat şeklini de etkiler. Dolayısıyla zanaatkârlığı aynı zamanda bir hayat biçimi olarak tanımlamak yanlış olmaz.

Kentin tarihi ve kimliği için önemli bir değere sahip olan zanaat mekânları çoğunlukla tarihî kent merkezlerindeki alanlarda yoğunlaşmaktadır. Bu mekânlar kentin sosyal, ekonomik ve kültürel yapısını geçmişten günümüze ulaştırabilen alanlardır ve zanaatkârların varlığıyla anlamını ve canlılığını koruyabilmektedir. Tarihî kent merkezlerinde aynı zanaat türünü icra eden zanaatkârlar çoğunlukla bir arada bulunurlar ve bu mekânlar genellikle o zanaat türü ile isimlendirirler.

Toplumların yaşam biçimlerini, düşüncelerini ve inanışlarını yansıtan bir olgu olan kültürel yapı, çevre koşuları ve dönemin olanaklarından etkilenmektedir. Aynı zamanda, temsil ettikleri dönemin sosyal, toplumsal ve ekonomik koşullarına göre oluşan toplumsal tercihler mekân oluşumlarını da biçimlendirir. Bu durum, kente o dönemde yüklenen ekonomik, sosyal ve kültürel birçok faktörle de ilişkilidir. Bütün bu gelişmeler zanaat ve zanaat mekânlarını da etkilemektedir. Dolayısıyla, değişen dönemlerle oluşan yeni toplumsal nitelikler ve düşünceler, zanaatların şekillenmesinde önemli rol oynamaktadır. ${ }^{1}$

1 Elif Tuğba Doğan, "Kitap İncelemesi: Richard Sennett: Zanaatkâr," Ankara Üniversitesi Sosyal Bilimler Fakültesi Dergisi 65 (2010), 299-306. 
Dolayısıyla, süreç içerisinde sosyo-ekonomik ve kültürel yapı, üretim-tüketim ilişkileri tarihî kent merkezlerinde değişimlere sebep olmuştur. Zaman içerisinde oluşan farklı kentsel kullanımlar mekânsal, işlevsel müdahaleler, mekânsal ve kullanıcı davranışlarında farklılaşmaları beraberinde getirmektedir. Değişen yaşam koşulları geleneksel ve küçük imalathanelerin yer aldığı tarihî kent merkezlerinde geleneksel üretime olan talebin azalmasına yol açmıştır. Hâlbuki tarihî kent merkezlerinde doğan geleneksel üretim kentin kimliğini ve kültürünü yansıtan değerli unsurlardan biridir ve bu zanaatların korunması ve canlandırılması kentlerin kültür ve kimliklerinin sürdürülebilirliği bakımından önemlidir.

Bu bağlamda, literatürde çeşitli araştırmalar bulunmaktadır. İncelenen çalışmalarda genel olarak, geleneksel üretime dayalı zanaat dallarının kent kimliği ve kültürünün sürdürülebilirliği açısından önemi ve gerekliliği vurgulanmakta, bunu sağlayabilmek için sosyal ve mekânsal birtakım önerilerde bulunulmaktadır. Ökten ve Evren'in araştırması, Kapalı Çarşı ve çevresindeki hanlarda o bölgenin kimliğini oluşturan kuyumculuk zanaatının kendi faaliyet alanını, tabandan gelen katılımc bir modelle canlandırılması yönündedir. Zanaat Eksenli Canlandırma adıyla sunulan bu modelde, söz konusu alandaki esnafin yapı, ada veya bölge ölçeğinde çeşitli düzlemlerde örgütlenerek koruma, canlandırma ve gelişme projelerinin sorumluluğunu üstlenmesine uygun bir ortam hazırlamak için neler yapılabileceği tartışılmaktadır. ${ }^{2}$ Diğer bir çalışmada ise kentsel politikalar üretirken o kentin geleneksel üretimine ve kentin mekânına çok boyutlu bir yaklaşım kurgulanması gerekliliği önemli bir şekilde vurgulanmaktadır. Kentsel politikalarda çok boyutlu yaklaşıma İstanbul'da Tarihî Kent Merkezinin Somut Olmayan Kültür Mirasıyla Birlikte Sürdürülmesi İçin Bir Öneri olarak geliştirilen "Kuyumculuk Mahallesi” örneği gösterilmiştir. Araştırmacılar, geleneksel üretimdeki ustaları birer kültür mirası olarak nitelendirir ve kuyumcu ustaları için Kapalıçarşı'nın öneminin çok büyük olduğundan söz etmektedirler. Bu sebeple bu bölgede yapılacak olan çok boyutlu bir planlama örneği, İstanbul'un başka yerlerine de örnek teşkil edebilir. ${ }^{3}$ Turan'ın endüstri karşısında zanaat ve tasarım ilişkileri ve çelişkilerini ortaya koyduğu çalışmasında; zanaatların bazı özgün tasarım çalışmalarının uygulamaya dönüşmesini olanaklı kıldığı örneklenmiştir. Erken Cumhuriyet Dönemi eşya üretim ortamında, tasarımın endüstri ve zanaatla nasıl ilişkilendirildiği ortaya konulmuştur. Çalışma sonucunda, Türkiye'de Erken Cumhuriyet Dönemi'nde ulusal ve uluslararası modern tasarım tartışmalarında geleneksel üretime ait bilgi birikiminin kullanılmasının sistemli bir biçimde ele alınmadığı, bununla birlikte yapılan tüm çalışmaların bu bilgiye sahip zanaatkârlar sayesinde olanaklı kılındığ 1 görülmüştür. ${ }^{4}$

2 Ayşe Nur Ökten ve Yiğit Evren, "İstanbul'da Geleneksel Kuyumculuk Sektöründe Yıkımın Coğrafyası: Zanaatkâr Gözüyle Mekân ve Yer”, 4. Kentsel ve Bölgesel Araşstırmalar Sempozyumu Bildiri Kitabı (Mersin: Kentsel Bölgesel Araştırmalar Merkezi Yayınları, 2013), 652-660.

3 Ayşe Nur Ökten ve Yiğit Evren, "Somut Olmayan Kültür Mirasının Sürdürülmesi İçin Üç Sektörlü Bir Model: İstanbul Tarihi Kent Merkezi İçin Kuyumculuk Mahallesi Önerisi," Planlama Dergisi 23 (2013), 35-44.

4 Gülname Turan, “Türkiye'de Erken Cumhuriyet Dönemi Zanaat ve Endüstri Üretiminde Tasarım” (Doktora 
Şatır, çalışmasında zanaat üretimlerinin diğer üretim türleriyle ilişkisini incelemeyi ve gelecekteki önemini sorgulamayı amaçlamıştır. Çalışma zanaat üretimlerini incelemekte, sürdürülebilirlik bağlamında günümüzde zanaata verilen önemi araştırmakta ve insanların gelecekte bu üretim tarzına yeniden ihtiyaç duyabileceğine vurgu yapmaktadır. Çalışmanın sonuçlarında, Türkiye'de zanaat üretiminin terk edilmemesi gerektiği vurgulanmaktadır. Zanaat kavramının değerini artırmak ve sürdürülebilirliğini sağlamak için gençlerin bir zanaat dalında eğitilmesi ve yetkin olmasının önemine değinilmektedir. ${ }^{5}$ Zanaat ve halk sanatlarını bağlamında yaratıcılığı stratejik bir unsur olarak ele alıp kentler arasındaki iş birliklerini ortak bir çerçevede değerlendirmeyi amaçlayan çalışmasında Yalçın, UNESCO tarafından zanaat ve halk sanatları unvanı verilen kentler için çeşitli incelemeler yapmıştır. Sonuç olarak günümüz küresel dünyasında birbirine benzeyen insanlar, mekânlar ve tarzlar oluşmasının yerel kimliğin ön plana çıkmasını sağladığını, bu süreçte somut olmayan varlıklar olarak nitelendirilen zanaat ve halk sanatlarının, halk katılımı ile birlikte kültür politikalarının oluşturulmasında önemli bir etmen olduğunu ve böyle bir politika oluşturulmasının zorunluluk olarak tanımlanması gerektiğini belirtmektedir. ${ }^{6}$

Çalışma alanı olarak seçilen Trabzon kenti ticaret ve zanaat bağlamında köklü bir geçmişe sahiptir. 15. yüzyıldan günümüze kadarki süreçte zengin ve önemli bir ticaret kenti olarak bölgenin merkezi olma özelliğini korumuştur. Kentin farklı bölgelerinde farklı zanaatlarla uğraşan birçok usta yetişmiştir. Bu zanaatkârların ürettiği ürünlerin satıldığ1 pazarlar, çarşıllar, hanlar, bedestenler kentin kimliğini ve kültürünü yansıtan mekânlar olarak günümüzde de varlığını sürdürmektedir. Ancak Anadolu'nun birçok kentinde olduğu gibi kentleşme sürecinde tüketim alışkanlıklarının değişmesi, yeni ticaret ve hizmet türlerinin yaygınlaşması geleneksel üretimi ve mekânlarını etkilemiştir. Bu tür gelişmeler sonucunda özellikle genç nüfus yeni ve alternatif iş kollarına yönelmiştir. Dolayısıyla, usta-çırak ilişkisinin önemli olduğu zanaatta, zanaat ustaları yeni çıraklar yetiştirememiştir. Bu gelişmeler zanaat kollarının her geçen gün önemini kaybetmesine sebep olmuştur. Bu da gelecekte zanaatın sürdürülebilirliği için önemli bir sorundur.

Sözü edilen sorunlara rağmen kentte geleneksel biçimde üretim yapan bazı zanaat türleri hâlen varlığını sürdürmektedir ve kentin kimliğinde önemli olan bazı mekânlara (Kunduracılar Caddesi, Bakırcılar Çarşısı gibi) referans vermektedir. Bu mekânlarda tarihî dokunun kısmen de korunuyor olması önemlidir. Dolayısıyla, kentteki zanaat mekânlarının sürdürülebilirliği, kent kimliği ve kültürünün yaşatılması için zanaat mekânlarına yönelik sorunların çözümü, potansiyellerin değerlendirilmesi ve korun-

tezi, İstanbul Teknik Üniversitesi, 2009), 217-227.

5 Seçil Şatır, "Sürdürülebilirlik Temelinde Zanaat Üretimi ve Gelecekteki Önemi”, 15. Üretim Araştırmaları Sempozyumu Bildiri Kitabı (İzmir: Nobel Akademik Yayıncılık, 2015), 811-819.

6 Bilal Yalçın, "Nasıl Zanaat ve Halk Sanatları Şehri Olunur,” Uluslararası Türk Dünyası Turizm Araştırmaları Dergisi 1 (2016), 22-31. 
ması gerekmektedir. Bu durum, kent kimliği ve kültürü bakımından zanaat ve zanaat mekânlarının sürdürülebilirliğinin önemini belirten yukarıda sözü edilen çalışmalarda da vurgulanmaktadır.

Bu çalışmada önemli ticaret ve zanaat geçmişine sahip olan Trabzon kentinde tarihî süreç içinde zanaat ve zanaat mekânlarının dönüşümünü hem mekânsal hem de zanaatkârların görüşleri doğrultusunda sosyal açıdan irdelemek, bu mekânların canlandırılması, korunması ve sürdürülmesine yönelik öneriler geliştirmek amaçlanmaktadir.

\section{Çalışma Alanı}

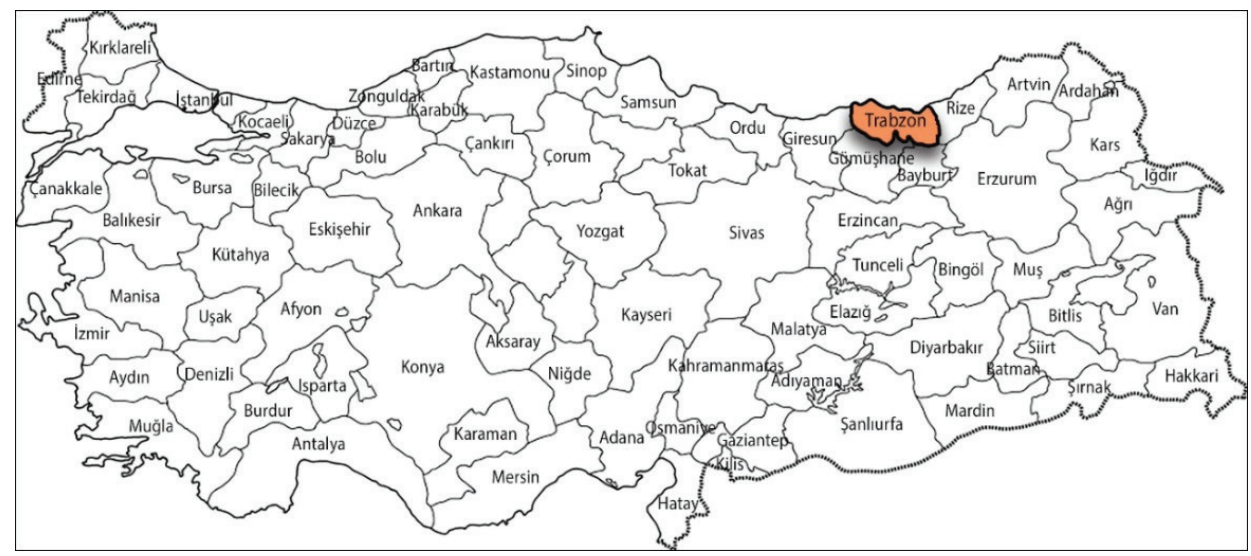

G. 1: Trabzon'un Ülke İçindeki Konumu (Nurçin Seymen, 2018)

Çalışma kapsamında Doğu Karadeniz Bölgesinde yer alan Trabzon kenti ele alınmiştır (G. 1). Kent, tarihinin en erken dönemlerinden beri ticaret ile var olmuş ve en parlak zamanlarını ticaretin en yoğun olduğu dönemlerde yaşamıştır. Zamanla kentteki ticaretin önemi artmış ve kente farklı hizmet türleri de girmeye başlamıştır. Trabzon kentindeki ticaretin önemli bir bölümünü zanaatlar oluşturmuştur. Ayakkabıcılık, ahşap işçiliği, dokumacılık, hasır bilezik yapımı, bakırcılık, gümüşçülük, yorgancılık gibi zanaatlarin geçmişte kent ticaretinde önemli bir yeri olduğu anlaşılmaktadır.

Çalışma kapsamında kentteki zanaat ve zanaat mekânları kent bütününde irdelenmiştir. Ancak kentin ana merkezini oluşturan ve tarihî kent merkezinin de içinde yer aldığı ve ticaret ile zanaatın en yoğun bulunduğu alanlar Cumhuriyet, Çarşı, Çömlekçi, Gazipaşa, İskenderpaşa, Kemerkaya ve Pazarkapı Mahalleleri olduğundan bu bölgeler esas çalışma alanını oluşturmaktadır (G. 2). 


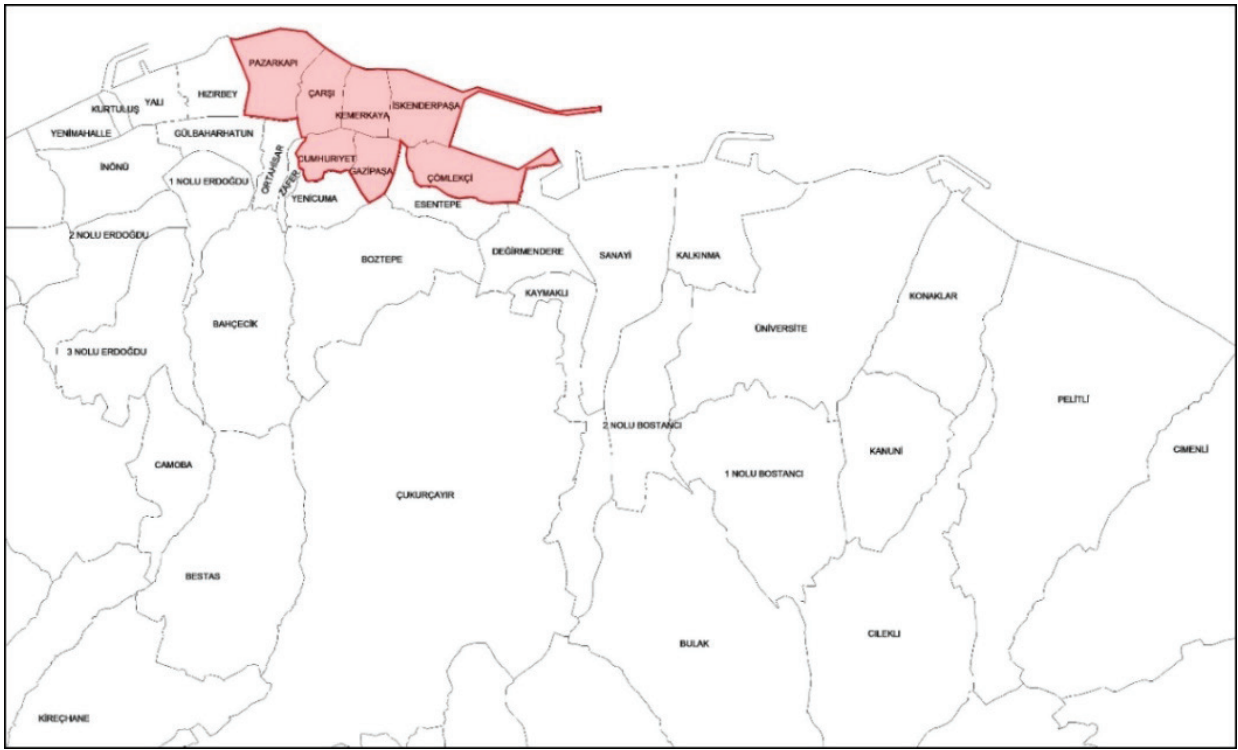

G. 2: Çalışma Alanındaki Mahalleler (Nurçin Seymen, 2018)

Kent kimliği ve kültürüne dair mekânsal, işlevsel izler taşıyan, geleneksel üretimin yapıldığı en önemli bölge olan tarihî kent merkezi de bu alan içinde yer almaktadır. Özellikle Kemeraltı bölgesi, kentin tarihî kimliğinde önemli olan hanlar, bedesten ve geleneksel çarşının olduğu alandır. Bakırcılar Çarşısı, Çarşı Cami, Alacahan, Taşhan ve Bedesten önemli yapıları barındırmaktadır. Tarihî kent merkezinde yoğunlaşan zanaatlar Semerciler Caddesi ve devamında Kunduracilar Caddesi boyunca devam etmektedir (G. 3).

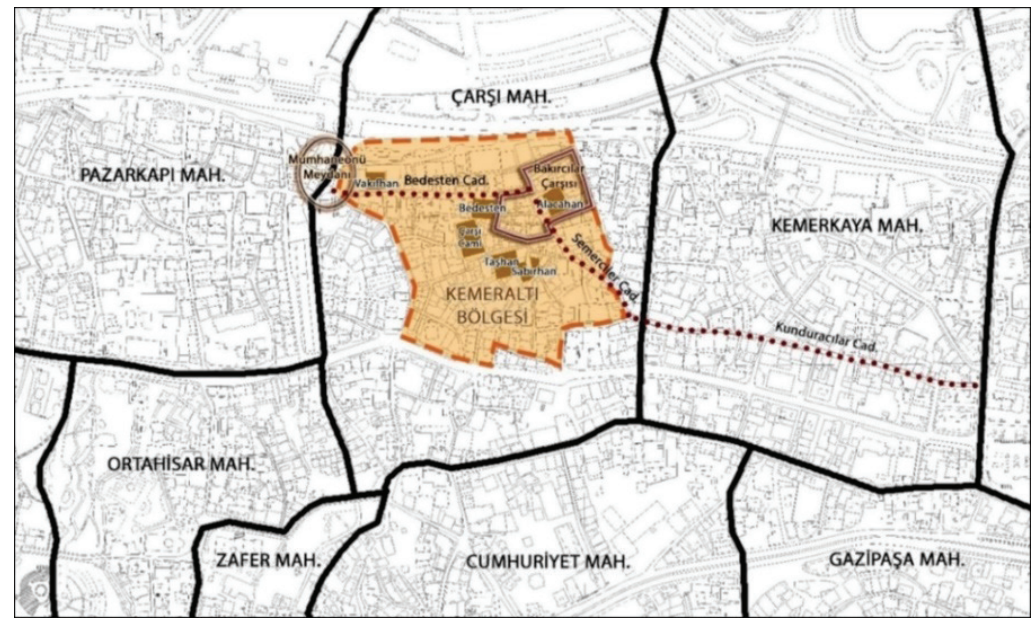

G. 3: Kemaraltı Bölgesi ve Zanaat Mekânları, (Nurçin Seymen, 2018) 


\section{Yöntem}

Çalışmada yöntem olarak literatür araştırması, alan çalışması/yerinde tespit, gözlem, fotoğraflama ve zanaatkârlarla görüşme tekniği kullanılmıştır.

Literatür Araştırması: Konu ile ilgili genel literatür araştırması yapılmıştır. Trabzon kentinin geçmiş dönemlerdeki zanaat ve zanaat mekânlarına yönelik bilgi kaynağ niteliğindeki kitabeler, Şer'iyye Sicilleri, Seyahatnameler, Salnameler, haritalar, fotoğraflar, resimler, konu ile ilgili yapılan tezler, yazılan kitaplar ve 1967-1968 yılları arasında yapılan Trabzon kenti analitik etüt çalışması incelenmiştir.

Alan çalışması: Bu aşamada günümüzdeki zanaat ve zanaat mekânları yerinde tespit edilmiştir. Geçmişteki zanaat mekânları için uzun yıllardır zanaatkârlık yapan ustalarla, kenti çok iyi bilen ve hâlâ yaşamını devam ettiren kişilerle görüşülerek günümüzde yok olmuş ya da yer değiştirmiş zanaat mekânlarının kentteki dağılımı tespit edilmiştir. Tüm bu veriler haritalandırılmıştır. Alan çalışmasından elde edilen veriler geçmiş dönem (1960 ve öncesi) ve günümüz (2018 y1lı) olmak üzere iki şekilde haritalandırılarak zanaat mekânlarının kentteki mekânsal değişim-dönüşümü ortaya konmuştur. Görüşmelerden elde edilen veriler de SPSS istatiksel programla analiz edilmiş, grafik ve tablolara dönüştürülerek yorumlanmıştır.

Zanaatkârlarla görüşme: Zanaatkârların cinsiyet ve yaş dağılımı, meslekte geçirdikleri süre, bu mesleği devam ettirme ve bulundukları mekânı tercih etme sebepleri ve memnuniyet düzeyleriyle ilgili mesleklerine yönelik sorunları tespit edebilecek nitelikte sorular hazırlanarak yapılandırılmış görüşme tekniği ile zanaatkârlarla görüşülmüştür. Çalışma alanında bulunan 370 zanaatkârın \%10 örneklemi alınarak görüşme yapılacak zanaatkâr sayısı tespit edilmiştir. Ancak sayısı 10'un altında olan zanaatkârların tümüyle görüşme yapılmıştır. Bunun sonucunda görüşme yapılan zanaatkâr sayısı, mobilya imalatçısı (10), süpürgeci (2), kuyumcu (14), bakırcı (10), demirci (3), ayakkabıcı (6), yorgancı (5), terzi (7) olmak üzere toplamda 57 kişidir.

Çalı̧̧manın Kapsamı: Tarih boyunca, zanaatlara ilişkin sınıflandırmalar üretim biçimine göre yapılmıştır. Yapılan çalışmada da zanaatlar; yaşam türleri ve hammaddeye bağlılık göz önünde bulundurularak 1964 yılı Esnaf ve Sanatkâr Yasası'ndaki ayrıma göre sınıflandırılmıştır. Buna göre aşağıdaki gibi sınıflama yapılmıştır:

- Maden İşleri: Kuyumculuk (hasır, kazaziye, telkâri, gümüşçülük) bakırcılık, demircilik ve çömlekçilik,

- Ağaç İşleri: Marangozluk, sandıkçılık, sepetçilik ve süpürgecilik,

- Deri İşleri: Dericilik ve ayakkabıcılık,

- Dokuma İşleri: Terzilik ve yorgancılık 


\section{Tarihsel Süreçte Trabzon'da Ticaret ve Zanaat}

Trabzon kenti ticaret ve zanaat bağlamında köklü bir geçmişe sahiptir. Kent İpek Yolu'nun sonunda kurulmuş önemli ticaret ve liman kentidir. İlkçağlardan itibaren Roma, Bizans ve Osmanlı İmparatorluğu dönemlerinde bulunduğu coğrafyanın siyasi, askerî ve ekonomik süreçlerinin yapılanmasında önemli olmuştur. İran Transit Yolu'nun başlangıcında bulunma, Doğu ve Güneydoğu Anadolu Bölgeleri'nin iskelesi olma gibi özelliklerinden dolayı bölge sürekli ülkeler arası rekabete tanıklık etmiştir. ${ }^{7}$ Ortaçağ' da Bizans döneminde Trabzon ticari önemini sürdürmüştür. Doğuda Hindistan, kuzeybatıda İran, güneyde de Kuzey Suriye ve Doğu Anadolu bölgelerinden kara yolu ile gelen çeşitli mallar, Trabzon Limanı üzerinden Konstantinopolis'e, buradan da Akdeniz ve Avrupa ülkelerine gönderilmektedir. Trabzon kenti İslam ülkeleri için batıya açılan bir kapı olduğundan, bu ülkeler için de büyük bir öneme sahiptir. ${ }^{8}$

10. yüzyılda Karadeniz, kendine kıyısı olan ülkelerin iç denizi durumuna gelmiştir. 13. yüzyılın ikinci yarısından sonra Karadeniz ticareti bir pazar niteliğinde dünya ticaretinde yer almaya başlamıştır. Bu süreçte Karadeniz’de önemli bir liman olan Trabzon'daki yoğun ticari hayat 14. yüzyıl boyunca sürmüş, Trabzon'un uluslararas1 ticarete açılması genişleyerek devam etmiştir. ${ }^{9}$ 15. yüzyılda Trabzon hem önemli bir ticaret şehri hem de bölgenin transit merkezi konumuna gelmişstir. Osmanlı Dönemi'nde, kentte gerçekleşen birçok yenilik limanı daha da öne çıkarmış ve ticareti geliştirmiştir.

Bu gelişmeler kentte birçok hanın kurulmasına sebep olmuştur. Özellikle hanların bulunduğu sokaklarda ticaret ve zanaatlar bir arada konumlanarak gelişmiştir. Merkezinde bedestenlerin yer aldığı etrafında hanların, dükkânların bulunduğu, her sanat dalının ayrı bir dükkân sırasına sahip olduğu, hepsinin bir pazar yani çarşıyı meydana getirdiği ve Osmanlı devletinin geneline yayılmış bu çarşı tipinin, Trabzon'da da mevcut olduğu görülmektedir. Her meslek gurubu kendisine ait çarşıda faaliyet göstermekteydi.

16. yüzyıla gelindiğinde artık kent içinde ticaret ve zanaat türlerinin belirli sokaklarda ve çarşılarda yoğunlaştığı, bu mekânların içinde bulunduğu ticaret ve zanaat türleri ile anılmaya başladığı görülmektedir: Paşmakçılar Çarşısı, Kuyumcular Arastası ve Debbağın Çarşısı gibi. Altın ve gümüş telkâri işlerinin ve hasır bileziklerin yapıldığı Kuyumcular Arastası kentin en etkili mekânlarından biriydi. Mutaflar Çarşısı (kıl dokunan ve satılan çarş1), Kasım Beşe Çarşısı, Yüncüler Çarşısı, Abacılar Çarşısı, Kazancılar Çarşısı, Saraç Çarşısı, Baklacılar Çarşısı, Attar Çarşısı, Balıkçılar Çarşısı, Gazazlar Çarşısı, Haffaflar Çarşısı ve Galle Pazarı (Hububat Pazarı) gibi çarşılar

7 Murat Taşkın, “Trabzon'da Ticaret," Trabzon (Trabzon: Eser Ofset Matbaacılık, 2013), 14-25.

8 Oktay Belli ve Gündağ Kayaoğlu, Trabzon'da Bakırcılık Sanatının Tarihsel Gelişimi (İstanbul: Arkeoloji ve Sanat Yayınları, 2002), 10-24.

9 Taşkın, “Trabzon'da Ticaret," 14-25. 
17. yüzyılda öne çıkan en önemli ticaret mekânlarıydı. Bunların dışında daha büyük ticaret yapan tüccarlar ise Bedesten'de toplanmışlardı. Bedesten, Trabzon çarşısının merkezinde yer alan şehrin en eski ticaret yapısıdır. Türk Bedestenleri içerisinde tek kubbeli olan tek örnektir. Yapının fetihten sonra 15. yüzyılın sonlarında yapıldığ bilinmektedir. ${ }^{10}$ (G. 4)

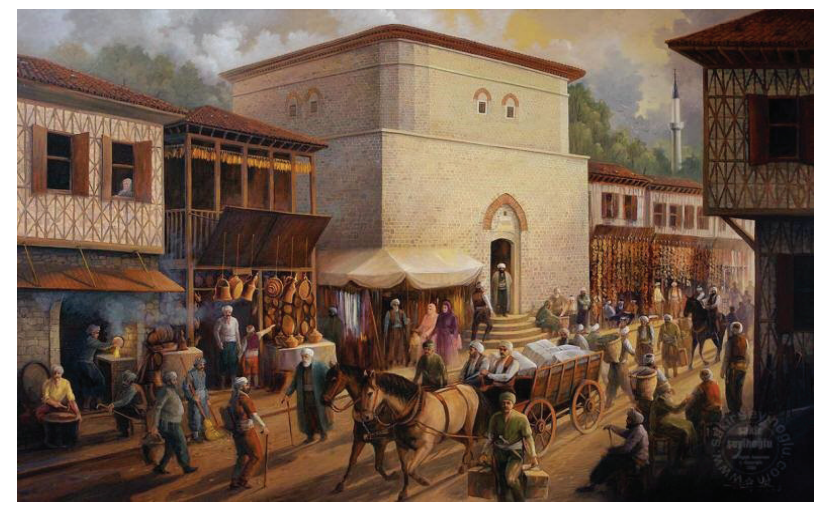

G. 4: 17. Yüzyıla Ait Bedesten Yapısı "Zağnos vadisi, Bedesten ve İpekyolu”, http://www.sanalbasin.com/zagnos-vadisi-bedesten-ve-ipekyolu-17106647/

Trabzon'un 18. yüzyılda hem eyalet merkezi olması hem de Karadeniz'in uluslararası ticarete açılması ile nüfusu artmış ve ticari hayatı daha da canlılık kazanmıştır. Bu yüzyılda kent hem pazar hem de transit ticaret merkezi olma görevini sürdürmüştür. ${ }^{11}$ Kentte farklı dallarda zanaatla uğraşan birçok usta bulunmaktaydı. Mumhaneönü, Alacahan, Taşhan, Bedesten, Bitpazarı, Tütüncü Çarşısı, Abacılar Çarşısı, Arasta Çarşısı, Çıkrıkçılar Çarşısı, Kazancılar Çarşısı, Semerciler Çarşısı, Çilingirler Çarşısı, Hallaçlar Çarşısı, Sipahiler Çarşısı, Debbağhane Çarşısı, Bakırcılar Çarşısı, Demirciler Çarşısı ve Uzun Çarşı zanaatkârların bir arada bulunduğu mekânlardı. ${ }^{12}$ (G. 5) Yine aynı yüzyılda kentte bakır üretimi yükselmişti ve üretilen bakırlar liman aracılığıyla İstanbul'a gönderilirdi. Bakırcılar, kazancılar ve kalaycılar bakırı işleyen esnaflardı. Zanaatkârların ürettiği bakır cezveler ise Fransa'ya satılmaktaydı. ${ }^{13}$

10 Necmettin Aygün, Onsekizinci Yüzyllda Trabzon'da Ticaret (Trabzon: Serander Yayınc1lık, 2005), 134-169.

11 Melek Öksüz, 18. Yüzyllda İkinci Yarısında Trabzon: Toplum-Kültür-Ekonomi (Trabzon: Serander Yayıncılık, 2006), 211-225.

12 Aygün, Onsekizinci Yüzyllda Trabzon'da Ticaret, 134-169.

13 Öksüz, 18. Yüzyllda İkinci Yarısında Trabzon: Toplum-Kültür-Ekonomi, 211-225. 


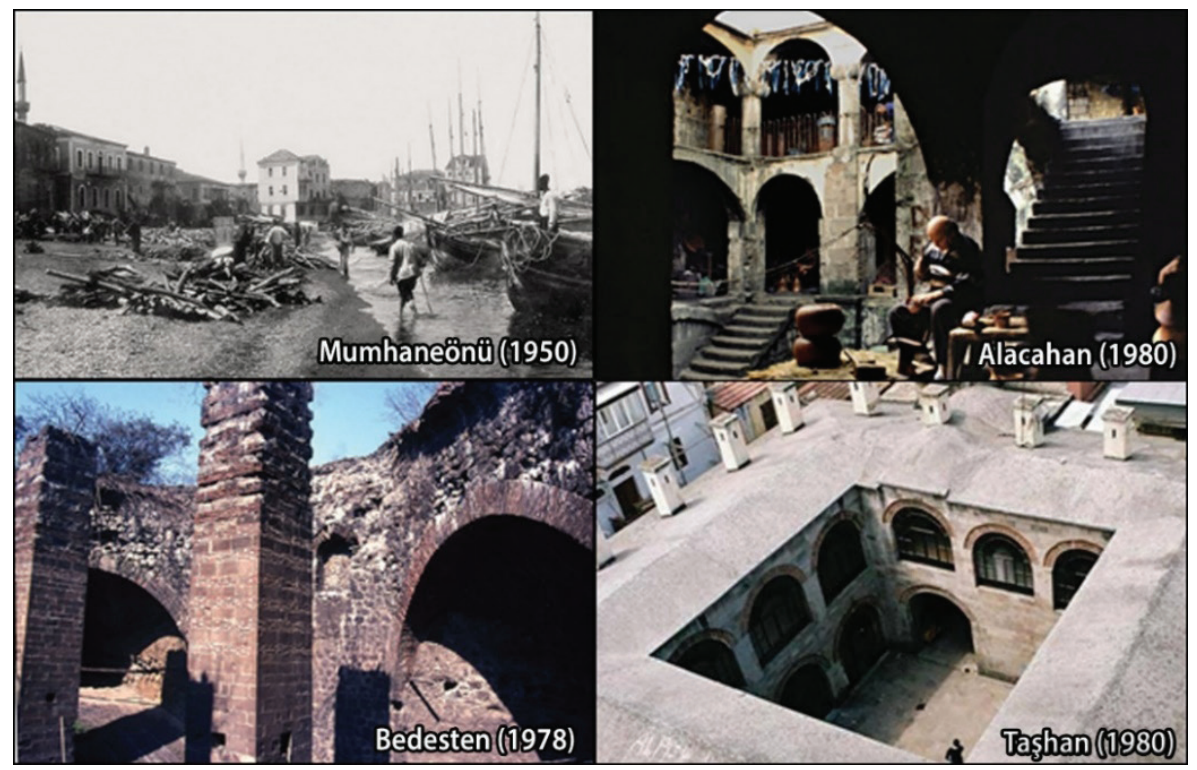

G. 5: Kentteki Önemli Çarşılar ve Ticaret Mekânları (Mustafa Reşat Sümerkan Fotoğraf Arşivi, 2018)

19. yüzyıla gelindiğinde, Karadeniz'de buharlı gemilerin kullanılmaya başlamasıyla Akdeniz' in transit nakliyatı Karadeniz'e dönmüştür. ${ }^{14} 19$. yüzyılın ikinci yarısında kentin gelişmesi hızlanmış, Avusturya, İsviçre, İran, Halep, İzmir, Diyarbakır, Bursa gibi yurt içi ve yurt dışı ülkelerden ve kentlerden gelen eşyalar da çarşılarda satılmıştır. Bu yüzyılın sonlarına doğru dokumacılık, demircilik ve kuyumculuk zanaatları çok gelişmiştir. Bu zanaatların yapıldığı hanların, bedestenlerin, çarşıların ve arastaların kentte oldukça önemli bir yeri vardır. 1873 tarihli Trabzon Vilayeti Salnamesi'nde o tarihlerde kent merkezinde 33 adet hanın olduğu belirtilmektedir. ${ }^{15}$ Yükler ve ticari mallar ise hayvanlarla ve özellikle deve kervanlarıyla taşınmıştır. ${ }^{16}$

Cumhuriyet'ten sonra ticaret, kent merkezindeki yeni iş merkezlerine doğru gelişerek devam etmiştir. Bu süreçte hanlar ve bedestenler eski canlılığını kaybetmeye başlamıştır. 20. yüzyıla gelindiğinde han ve bedestenlerin birçoğu kapanmış, ticaret daha çok pasajlar ve yol boyu ticaret şekline dönüşmüştür. 20. yüzyıl sonunda kentleşme ve kent nüfusunun artması, ticari işlevlerin gelişmesi ve yayılması sonucu kent merkezi yetersiz kalmış ve bir dönüşüm sürecine girmiştir. Bu süreç, geleneksel kent merkezinin genişlemesi ve yayılması şeklinde olmuştur. Bunun sonucunda tarihî kent merkezinde önemli mekânsal değişimler yaşanmıştır. Özellikle Kemeraltı Bölgesi,

14 Mustafa Reşat Sümerkan, Trabzon Yöresi Geleneksel El Sanatları (Trabzon: Serander Yayıncılık, 2008), 32-44.

15 Fatih Şahin, “Alışveriş Merkezlerinin Biçimlenmesinde Önemli Boyutlardan Kamusal Mekân ve Kamusallık Olgusu” (Yüksek lisans tezi, Karadeniz Teknik Üniversitesi, 2005), 30-34.

16 Sümerkan, Trabzon Yöresi Geleneksel El Sanatlarl, 32-44. 
Kunduracılar Caddesi, Mumhaneönü Bölgesi ve Semerciler Yokuşu'nda yoğunlaşan zanaat mekânları kapanmış ya da işlev değiştirmiştir. Ayrıca merkezde yer alan küçük imalathane gibi kullanımlar, merkez dışında oluşturulan küçük sanayi sitelerine (Ayakkabıcılar Sitesi, Marangoz ve Mobilyacılar Sitesi gibi) taşınmıştır. ${ }^{17}$ Bunun yanı sıra, günümüzde varlığını artık sürdüremeyen zanaatların Çömlekçi Mahallesi, Sandıkçılar Sokağı, Terziler Sokağı, Terzihan, Semerciler Caddesi, Kunduracılar Caddesi, Bakırcılar Çarşısı gibi mekân isimleri ile hâlâ yaşatılıyor olması da kentte zanaatın ne kadar önemli bir yer tuttuğunu göstermektedir.

Zaman içinde gerek nicelik gerekse mekânsal olarak değişen-dönüşen zanaatların bazıları (çömlekçilik, sandıkçılık, sepetçilik ve süpürgecilik gibi) tamamen yok olmuştur. Marangozluk, bakırcılık, demircilik, terzilik, yorgancılık, ayakkabıcılık gibi zanaatlar oldukça azalsa da varlığını sürdürebilmiştir. Kuyumculuk, hasırcılık, telkâri, kazazaziye gibi mevcut teknolojik, ekonomik ve sosyo-kültürel koşullara uyum sağlayarak ve gelişerek devam eden zanaatlar ise varlığını sürdürmektedir.

\section{Mekânsal Olarak Zanaat ve Zanaat Mekânlarının Değişimi-Dönüşümü}

Alan çalışması ve görüşme sonuçları, geçmişten günümüze zanaat türlerinin nicelik olarak giderek azaldığını ve mekânsal olarak da farklılaştığını göstermektedir (T. 1). Örneğin mobilya imalatçıları ve marangozlar geçmişte mekânsal olarak Pazarkapı Mahallesi ve Yenicuma Mahallesi'nde kümelenmekteydi. Günümüzde de bu zanaatın yine aynı bölgelerde özellikle Pazarkapı Mahallesi’nde kümelendiği ancak geçmişe göre sayısal oranda azaldığı, Yenicuma Mahallesi'nde ise tekil olarak kaldığı görülmektedir. Günümüzde marangoz ve mobilya imalatçıları kent merkezinde oldukça azalmış, Mobilyacılar Sitesi ve Sanayi Sitesine taşınmıştır.

Sandıkçılık geçmişte Trabzon için çok önemli bir kültür ögesiydi ve sandıkçılar Mumhaneönü Meydanı'na yakın, Kadınlar Pazarı ile karşılıklı konumda yer almaktaydı. 1980'li yılların sonunda kentte sandıkçılık bitmiş ve günümüze ulaşan sandıkçılık zanaatı kalmamış, yalnızca eskiden sandıkların yapıldığı mekân olan Sandıkçılar Sokağı, isim olarak varlı̆̆ını devam ettirmektedir (G. 6).

17 Yelda Aydın, “Kentsel Gelişme ve Kent Merkezlerinin Dönüşümü: Trabzon Örneği” (Yüksek lisans tezi, Karadeniz Teknik Üniversitesi, 2001), 16-22. 


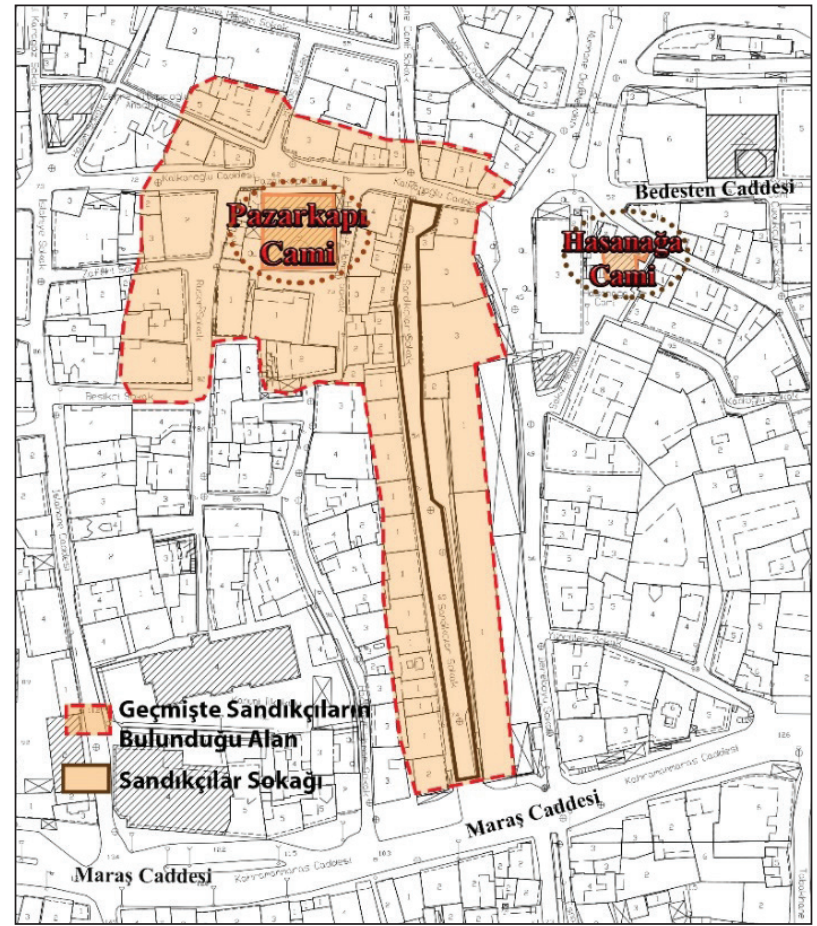

G. 6: Geçmişteki Sandıkçılık Mekânları ve Sandıkçılar Sokağı (Nurçin Seymen, 2018)

Bir başka zanaat dalı olan Süpürgeciler geçmişte Mumhaneönü Meydanı'ndan Kemeraltı'na geçişteki Bedesten Caddesi üzerinde yer almaktaydı (G. 7). Ancak teknolojinin gelişmesi süpürgecileri de etkilemiş ve günümüze yalnızca iki tane süpürgeci kalmıştır. Sepetçiler ise, Pazarkapı Mahallesi'nde Kalkanoğlu Caddesi’nde bulunmaktaydı ancak günümüzde sepetçilik zanaatı da kalmamıştır. 


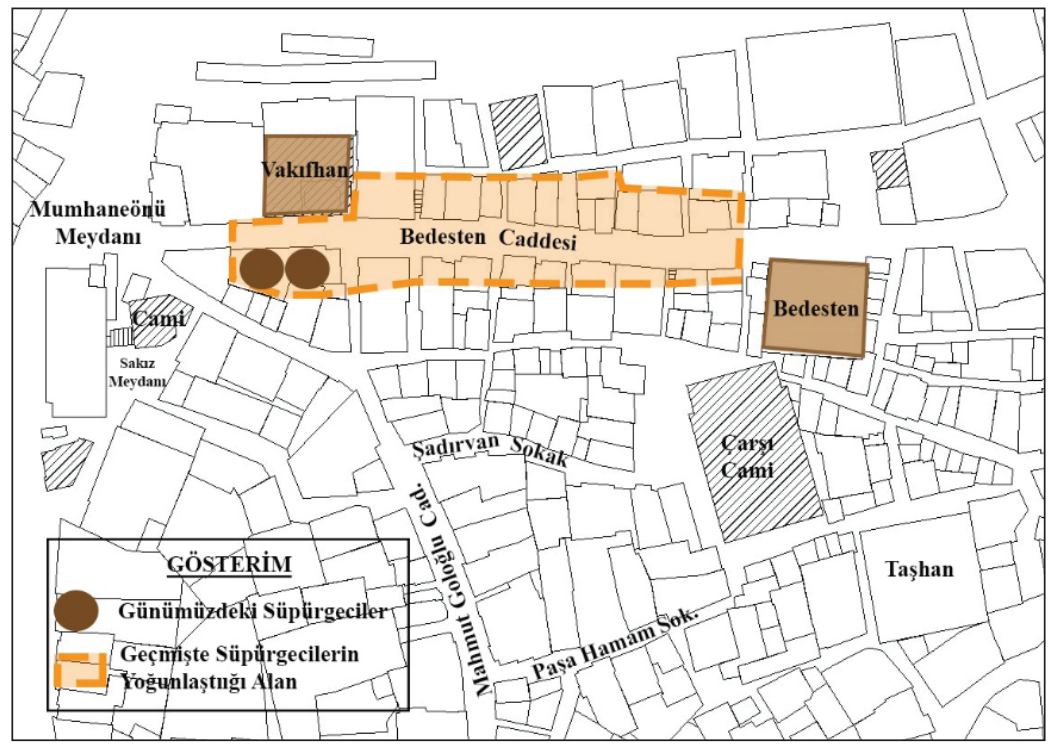

G. 7: Geçmişten Günümüze Kentteki Süpürgeciler (Nurçin Seymen, 2018)

Geçmişte ayakkabıcılık zanaatı Çarşı Mahallesi'nde bulunmaktaydı. Kentin önemli zanaatları arasında olan ayakkabıcılık, Kunduracılar Caddesi, Kemeraltı Bölgesi, Şükürhan (Pabuçhan) ve Tabakhane bölgelerinde öbek öbek yer almaktaydı. Günümüzde ayakkabıcılıkta el işçiliğinin terk edilmesiyle bu zanaatın nicelik olarak azaldığı ve mekânsal olarak da tekil konuma düştügü görülmektedir. Dericiler ise geçmişte, caddeye ismini veren Tabakhane Caddesi'nde yer almaktaydı (G. 8). Ancak günümüzde kentte dericilik kalmamıştır. 


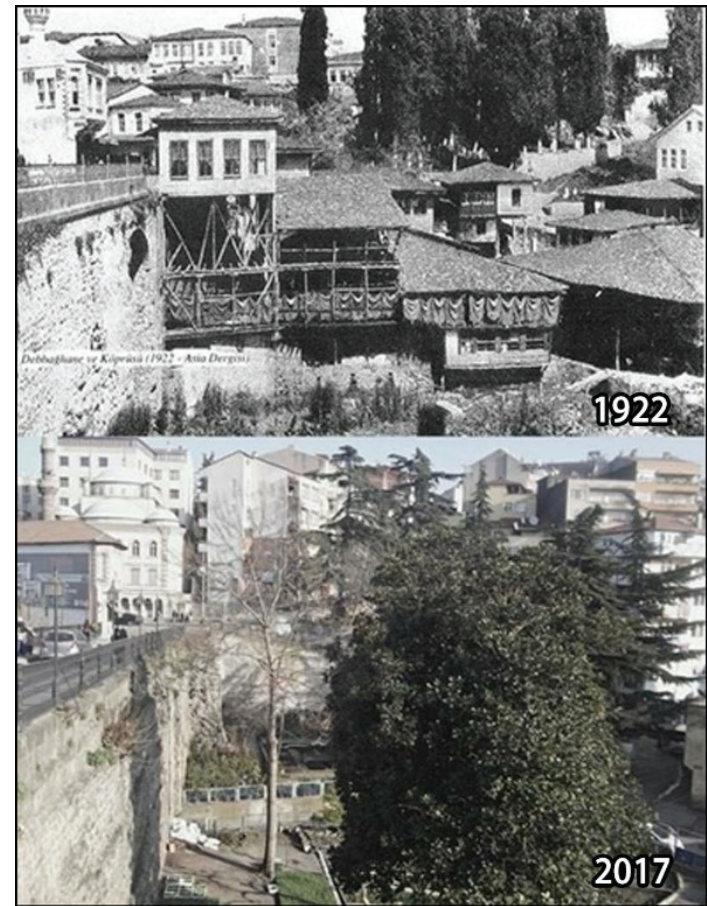

G. 8: Tarihî Tabakhane Köprüsü ve Çevresi, "Dabbağhane ve Köprüsü”, üstteki görsel http://www.eskiturkiye.net/3275/trabzon-tabakhane-koprusu-1922 ve alttaki görsel

(Nurçin Seymen, 2017)

Terzilik zanaatı ise Kemeraltı Bölgesi'nde yer alan Taşhan (Terzihan)'da kümeleniyordu. Günümüzde terzilik zanaatı yapanların birçoğu yine Taşhan'da bulunmaktadır (G. 9). Bir kısmı ise çalışma alanında kalan mahallerde dağınık şekilde yayılmıştır (G.13). Diğer zanaatlar gibi Terzilik zanaatı da kentte nicel olarak azalmıştır (T. 1). Bunda özellikle hazır giyim (konfeksiyon) sanayinin gelişmesi önemli bir etkendir. 


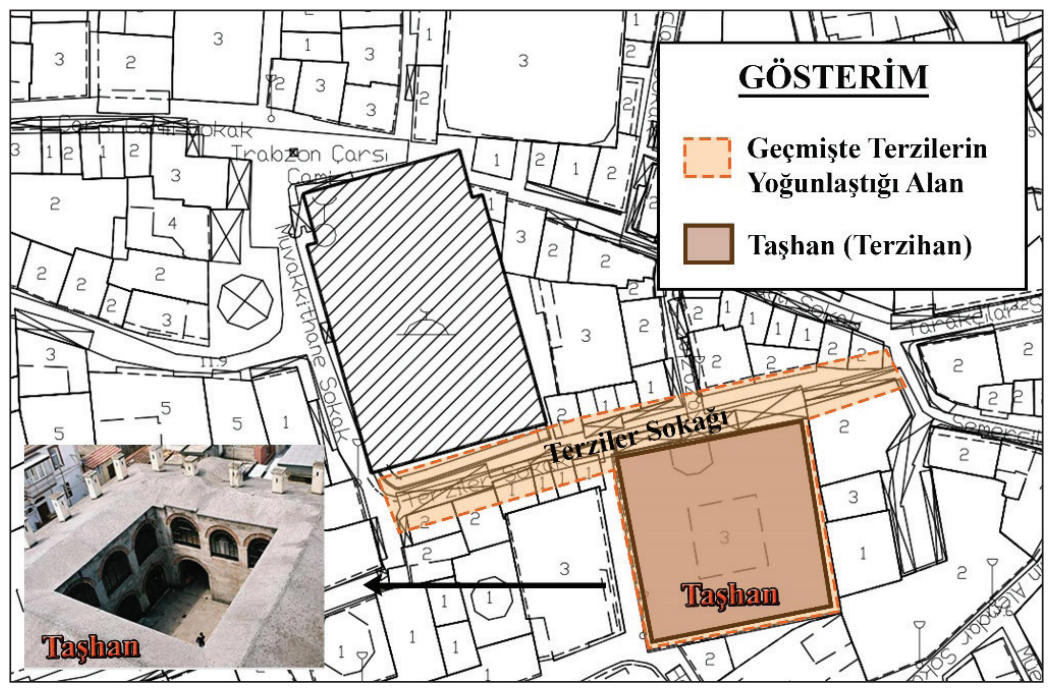

G. 9: Terzihan (Taşhan) ve Terziler Sokağı (Nurçin Seymen, 2018)

Geçmişte kentin hemen hemen her mahallesinde bulunan yorganc1lık ise en fazla Gazipaşa ve Ortahisar Mahallelerinde belirli sokaklar boyunca kümelenmişti. Günümüzde de yine aynı mahallelerde yorgancılık sürmektedir ancak yorgancıların sayısı azalmış ve tekil olarak faaliyet göstermektedirler (G. 10).

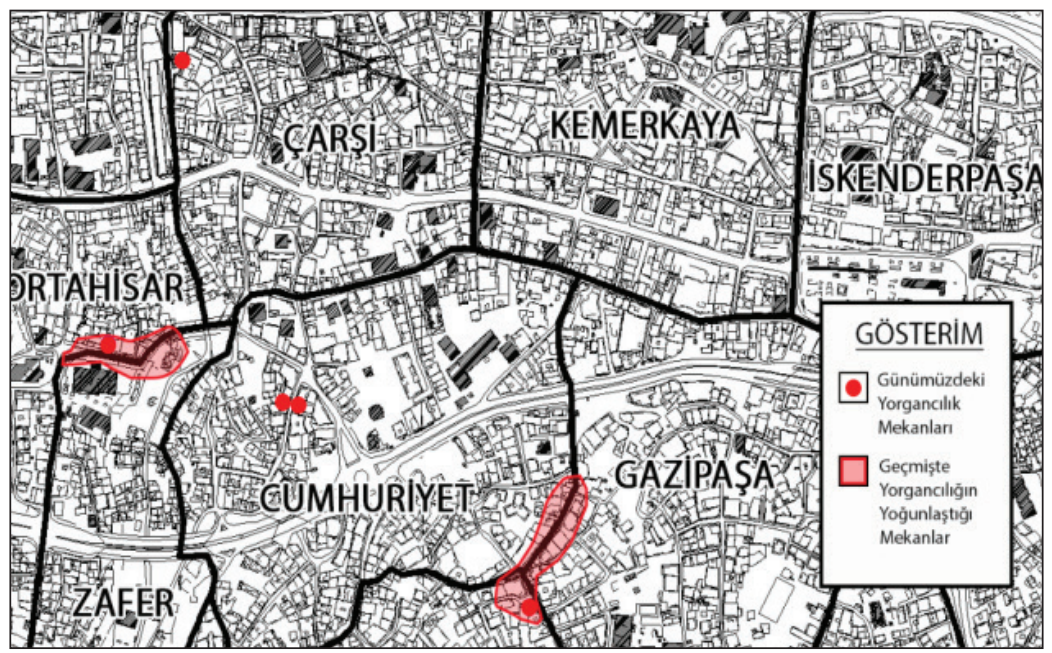

G. 10: Geçmişte ve Günümüzde Yorgancıların Yoğunlaştığı Bölgeler (Nurçin Seymen, 2017)

Kuyumculuk Trabzon'un en eski zanaatlarından biridir. Trabzon'a özgü kuyumculuk olarak nitelendirilen bu zanaat ile hasır örücülüğü, kazazlık ve telkâri yapılmaktadır. Trabzon hasırı, Türk kuyumculuk kültürünün önemli bir parçası olup sadece Trabzon kentinde üretilmektedir. Kuyumculuk zanaatında farklı bir örücülük dalı da kazazlıktır. Kazaz örücülüğ̈̈ Trabzon kentine has bir zanaat dalı olup ince gümüş 
tellerin ibrişim üzerine burulmasıyla şekil bulur. Bu ürünlerin başında kolye, küpe, bileklik ve tespih gibi el işi ürünler gelmektedir ${ }^{18}$ (G. 11). Geçmişte yoğun olarak Kemeraltı Bölgesi'nde yapılan bu zanaat, günümüzde güvenlik ve kent merkezine yakın olma gibi nedenlerle Kunduracılar Caddesi'ne taşınmıştır. Ayrıca diğer zanaatlara oranla nicelik olarak kentte artış göstermiştir (T. 1).

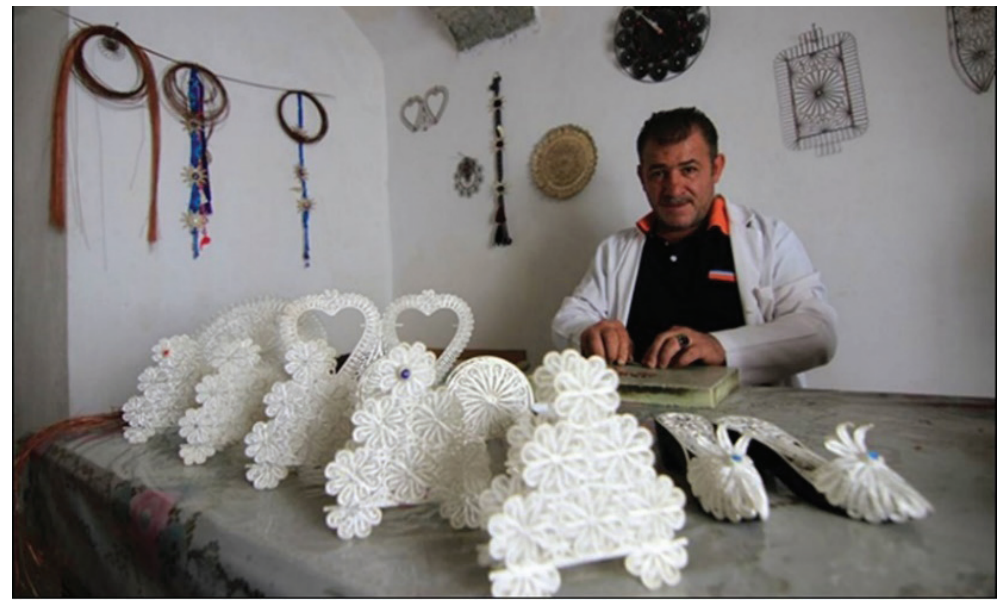

G. 11: 30 Yıllık Telkari Zanaatkârı Erkan Usta ve Telkari Örnekleri (Nurçin Seymen, 2017)

Kentteki önemli zanaatlardan biri olan ve tarihî kent merkezinde Kemeraltı Bölgesi'ndeki Alacahan, Alacahan Sokak ve Kazancilar Sokak'ta yer alan bakırcilık ise geçmişte konumlandığı aynı mekânlarda günümüzde de yer almaktadır. Ancak bakırcıların sayıları azalmış ve daha çok tekil olarak faaliyet göstermektedirler (G. 12)

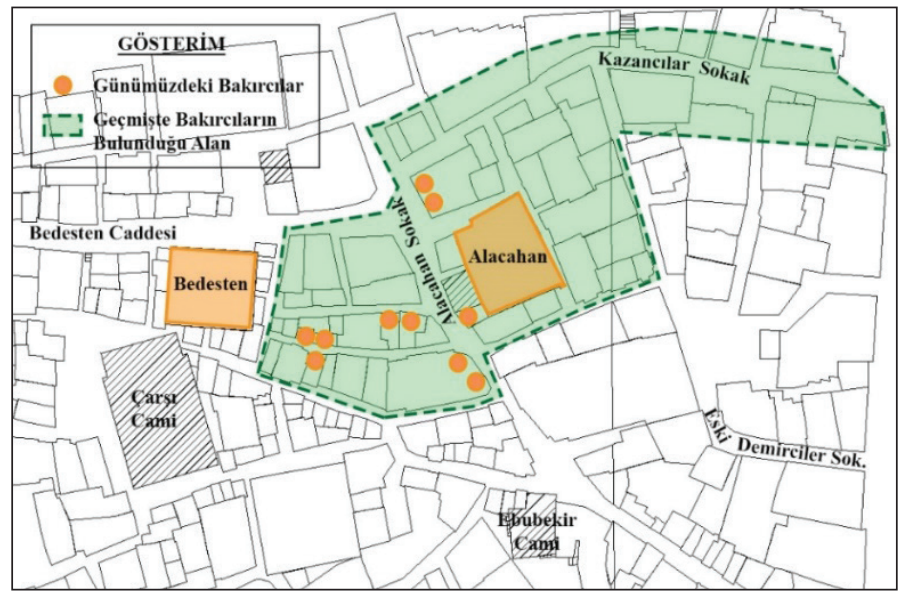

G. 12: Alacahan-Bedesten ve Yakın Çevresinde Yoğunlaşan Bakırcılar (Nurçin Seymen, 2018)

18 Nuri Durucu, “Trabzon Kuyumculuğu,” Uluslararası Karadeniz Havzası Halk Bilimi Araştırmaları Dergisi 1 (2015), 112-181. 
Demircilik zanaatı, Trabzon kentinde Osmanlı Dönemi'nden beri yapılmaktadır. Geçmiş dönemde Pazarkapı Mahallesi ve Bakırcılar Çarşısı çevresinde yoğunlaşmıştır. Yeni neslin talep etmediği bir meslek dalı olması sebebiyle ve gelişen teknolojiyle birlikte bu zanaat gün geçtikçe kaybolmaktadır. Günümüzde kent merkezinde (Pazarkapı Mahallesi) ve Sanayi Sitesi içerisinde varlığını azalarak devam ettirmektedir.

Trabzon'un liman kenti oluşundan dolayı geçmişte ticarette önemli bir paya sahip olan çömlekçilik limana yakın oluşundan dolayı Çömlekçi Mahallesi’nde gelişmişti (G. 13). Günümüzde çömlekçilik zanaatı ile uğraşan kimse kalmamıştır. Ancak eskiden çömleklerin yapıldığı yer olan Çömlekçi Mahallesi, mahalle adı olarak varlığını devam ettirmektedir.

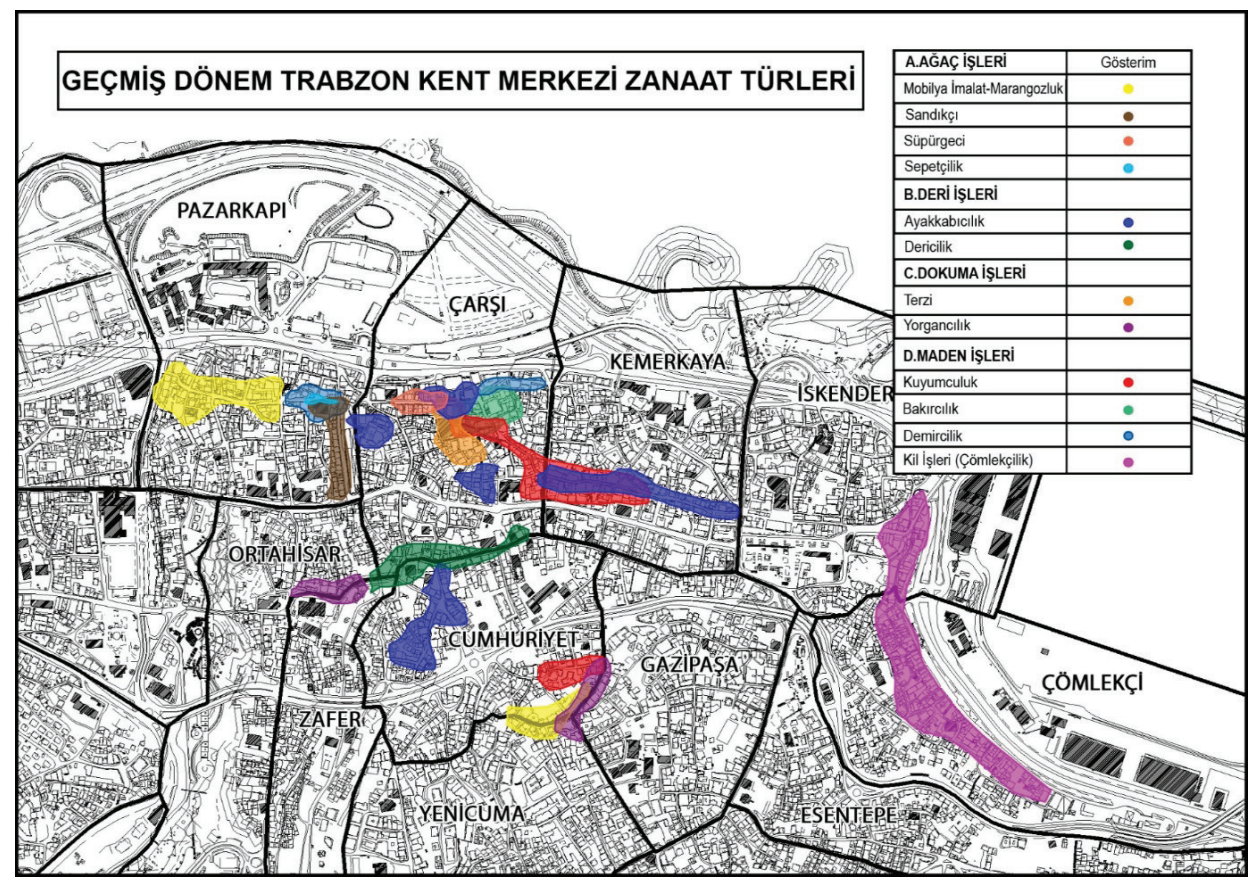

G. 13: Geçmiş Dönem (1960'lı yıllar ve öncesi) Trabzon Kent Merkezi Zanaat Türleri (Nurçin Seymen, 2018) 


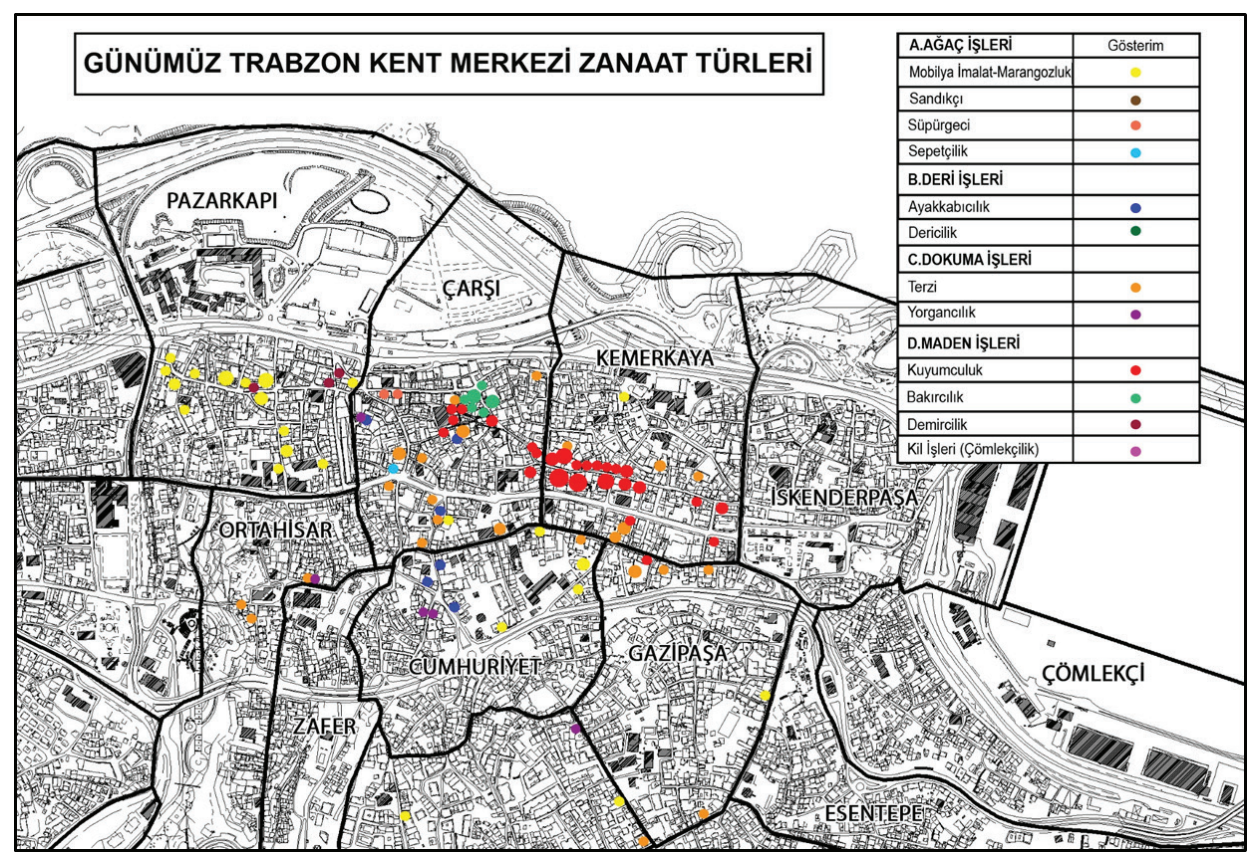

G. 14: Günümüz (2018 yılı) Trabzon Kent Merkezi Zanaat Türleri (Nurçin Seymen, 2018) 
Tablo 1. Geçmişten Günümüze Zanaat Dallarının Mekânsal ve Niceliksel Değişimi

\begin{tabular}{|c|c|c|c|c|c|c|}
\hline \multirow{2}{*}{$\begin{array}{l}\text { Zanaat } \\
\text { Dalları }\end{array}$} & \multicolumn{2}{|l|}{1960} & \multicolumn{2}{|l|}{2000} & \multicolumn{2}{|l|}{2017} \\
\hline & Mekânsal & Niceliksel & Mekânsal & Niceliksel & Mekânsal & Niceliksel \\
\hline $\begin{array}{c}\text { Mobilya } \\
\text { İmalat } \\
\text { ve } \\
\text { Marangozluk }\end{array}$ & $\begin{array}{l}\text { Kemerkaya Mah. } \\
\text { Cumhuriyet Mah. } \\
\text { Çarşı Mah. } \\
\text { Yenicuma Mah. } \\
\text { Pazarkapı Mah. }\end{array}$ & 128 & $\begin{array}{l}\text { Çarşı Mah. } \\
\text { Pazarkapı Mah. } \\
\text { Kemerkaya Mah. } \\
\text { Cumhuriyet Mah. } \\
\text { Fatih Mah. } \\
\text { Sanayi Mah. } \\
\end{array}$ & 78 & $\begin{array}{l}\text { Kaşüstü Mah. } \\
\text { Söğütlü Mah. } \\
\text { Çarşı Mah. } \\
\text { Pazarkapı } \\
\text { Mah. }\end{array}$ & 105 \\
\hline Sandıkçılık & $\begin{array}{l}\text { Pazarkapı Cami } \\
\text { ve çevresi }\end{array}$ & 21 & - & - & - & - \\
\hline Süpürgecilik & $\begin{array}{l}\text { Kemeraltı Bölgesi } \\
\text { (Bedesten } \\
\text { Caddesi) }\end{array}$ & 10 & \begin{tabular}{|l|} 
Kemeraltı \\
Bölgesi \\
(Bedesten \\
Caddesi) \\
\end{tabular} & 2 & $\begin{array}{l}\text { Kemeraltı } \\
\text { Bölgesi } \\
\text { (Bedesten } \\
\text { Caddesi) } \\
\end{array}$ & 2 \\
\hline Sepetçilik & $\begin{array}{l}\text { Pazarkapı Mah. } \\
\text { Kalkanoğlu Cad. }\end{array}$ & 1 & - & - & - & - \\
\hline Ayakkabıcılık & $\begin{array}{l}\text { Kemerkaya Mah. } \\
\text { (Kunduracılar } \\
\text { Cad) } \\
\text { Çarşı Mah. } \\
\text { (Kemeraltı Böl., } \\
\text { Şükürhan) } \\
\text { Cumhuriyet } \\
\text { Mah. (Tabakhane } \\
\text { Mevki) } \\
\end{array}$ & 18 & $\begin{array}{l}\text { Çarşı Mah. } \\
\text { (Kemeraltı Böl., } \\
\text { Şükürhan) } \\
\text { Cumhuriyet } \\
\text { Mah. (Tabakhane } \\
\text { Mevki) }\end{array}$ & 18 & $\begin{array}{l}\text { Çarşı Mah. } \\
\text { (Kemeraltı } \\
\text { Böl., Şükürhan) } \\
\text { Cumhuriyet } \\
\text { Mah. } \\
\text { (Tabakhane } \\
\text { Mevki) }\end{array}$ & 5 \\
\hline Dericilik & Tabakhane Cad. & - & - & - & - & - \\
\hline Terzilik & \begin{tabular}{|l} 
Kent Merkezinde \\
Yer Alan \\
Mahalleler \\
(Özellikle \\
Kemeraltı'daki \\
Taşhan/Terzihan) \\
\end{tabular} & 149 & $\begin{array}{l}\text { Kent Merkezinde } \\
\text { Yer Alan } \\
\text { Mahalleler }\end{array}$ & 86 & $\begin{array}{l}\text { Kent } \\
\text { Merkezinde } \\
\text { Yer Alan } \\
\text { Mahalleler }\end{array}$ & 71 \\
\hline Yorgancilık & $\begin{array}{l}\text { Gazipaşa Mah. } \\
\text { Ortahisar Mah. }\end{array}$ & 47 & $\begin{array}{l}\text { Yenicuma Mah. } \\
\text { Ortahisar Mah. } \\
\text { Cumhuriyet Mah. }\end{array}$ & 21 & $\begin{array}{l}\text { Yenicuma Mah. } \\
\text { Ortahisar Mah. } \\
\text { Cumhuriyet } \\
\text { Mah. }\end{array}$ & $\begin{array}{l}5 \\
.\end{array}$ \\
\hline Kuyumculuk & $\begin{array}{l}\text { Kemeraltı Bölgesi } \\
\text { (Bakırcılar } \\
\text { Çarşısı) }\end{array}$ & 34 & $\begin{array}{l}\text { Kunduracilar } \\
\text { Caddesi }\end{array}$ & 96 & $\begin{array}{l}\text { Kunduracilar } \\
\text { Caddesi }\end{array}$ & 146 \\
\hline Bakırcılık & $\begin{array}{l}\text { Kemeraltı Bölgesi } \\
\text { (Bakırcılar } \\
\text { Çarşısı, Alacahan } \\
\text { ve Bedesten } \\
\text { etrafinda) }\end{array}$ & 41 & $\begin{array}{l}\text { Bakırcılar Çarşısı } \\
\text { (Alacahan, } \\
\text { Alacahan Sokak } \\
\text { ve Kazancılar } \\
\text { Sokak) }\end{array}$ & 23 & $\begin{array}{l}\text { Bakırcılar } \\
\text { Çarşısı } \\
\text { (Alacahan, } \\
\text { Alacahan } \\
\text { Sokak ve } \\
\text { Kazancılar } \\
\text { Sokak) } \\
\end{array}$ & 10 \\
\hline Demircilik & \begin{tabular}{|l|} 
Bakırcılar Çarşısı \\
yakın çevresi \\
Pazarkapı Mah. \\
Sanayi Mah. \\
\end{tabular} & 18 & $\begin{array}{l}\text { Sanayi Mah. } \\
\text { Pazarkapı Mah. }\end{array}$ & 57 & $\begin{array}{l}\text { Pazarkapı Mah. } \\
\text { Değirmendere } \\
\text { yolu üzeri } \\
\text { Sanayi Sitesi } \\
\end{array}$ & 25 \\
\hline $\begin{array}{c}\text { Kil İşleri/ } \\
\text { Çömlekçilik }\end{array}$ & Çömlekçi Mah. & 4 & - & - & - & - \\
\hline
\end{tabular}




\section{Zanaatkâr Gözüyle Zanaat ve Zanaat Mekânlarının Değişimi-Dönüşümü}

Kent kimliğinde önemli bir değere sahip olan zanaat, bulunduğu mekânıyla, ustasıyla ve yaşam biçimiyle bir kültür mirası niteliği taşımaktadır. Bu bağlamda, zanaat mekânlarındaki; sosyal, ekonomik, kültürel ve mekânsal yapıyı zanaatkârların gözüyle tanımlamak önemlidir. Kentteki zanaatkârlarla yapılan görüşmelerde zanaatkârların cinsiyet ve yaş dağılımı, zanaatkârlık mesleğini devam ettirme süresi, zanaatı nasıl tanımladıkları, bulundukları mekânı tercih sebepleri, uğraştıkları zanaat türünün geçmiş ve günümüzdeki durumu, sorunları, zanaat mekânlarını ve zanaatkârı korumanın gerekliliği konularındaki görüşleri alınmıştır.

Görüşme yapılan zanaatkârların \%25'ini kuyumcular oluşturmaktadır. Çünkü kentte en aktif olarak varlığını sürdüren zanaat dalı kuyumculuktur. Görüşülen bakırcılık, demircilik, süpürgecilik, ayakkabıcılık, yorgancılık ve terzilik zanaatkârlarının oranı $\% 5$ ile $\% 18$ arasındadır. En düşük oran ise $\% 3$ ile süpürgecilik olup bu zanaat dalının artık kentte kaybolmak üzere olduğu görülmektedir.

Görüşülen zanaatkârların \%90'1 erkek, \%10'u ise kadındır. Erkeklere oranla sayıları az olan kadınların; kuyumculuk, yorgancılık ve terzilikle uğraştığı, diğer zanaat türlerinde yer almadığı görülmektedir. Mobilya imalatı, bakırcılık, demircilik ve ayakkabıcılık gibi zanaat dallarının yoğun kuvvet gerektirmesi kadınların bu zanaatlarda ustalaşamamasının sebebi olarak gösterilebilir.

Zanaatkârların yaş dağılımı bakımından, tüm zanaat dallarında özellikle 51-60 yaş aralığında bir yığılma olduğu (\%61), 30-40 yaş arası zanaatkârların ise oldukça düşük bir orana (\%3) sahip olduğu görülmektedir. Bu durum, zanaatın ve zanaatkârlığın emek ve sabır isteyen, uzun yıllar gerektiren bir olgu olduğunu göstermektedir. Yaş olarak en genç (30-40 yaş) olan zanaatkârlar kuyumculardır (\%36). Bu da kuyumculuk zanaatının geçmişte olduğu gibi günümüzde de talep edilen, kuşaktan kuşağa aktarılan bir meslek olduğunu kanıtlamaktadır. 81 yaş ve üzeri zanaatkârlar ise \%10 oranında yalnızca mobilya imalatında görülmüştür (G. 15).

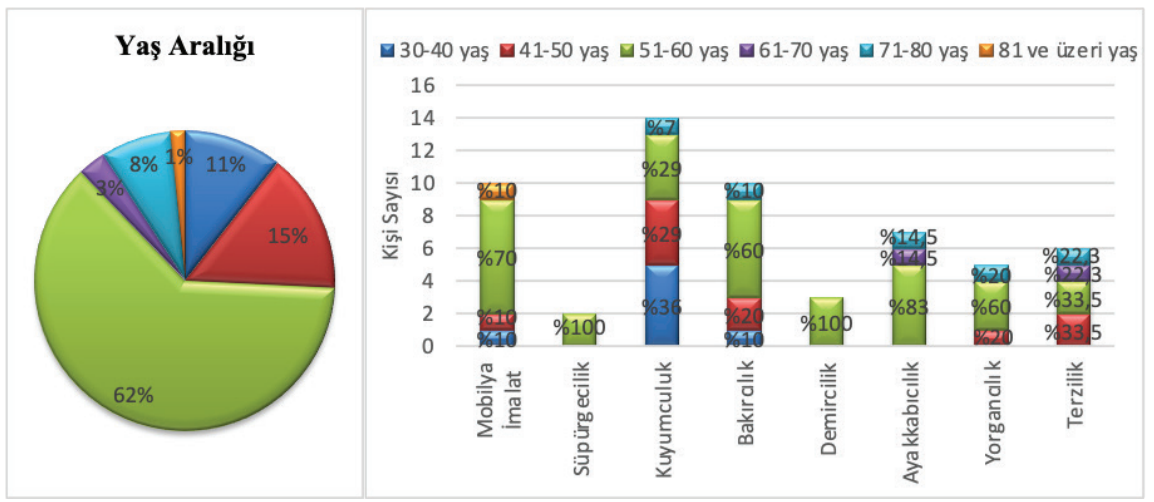

G. 15: Zanaatkârların Zanaat Türlerine Göre Yaş Dağılımları (Nurçin Seymen, 2018) 
Zanaatkârların eğitim durumları değerlendirildiğinde zanaatkârlar arasında \%71 oranıyla ilkokul mezunları en büyük paya sahipken, lise eğitimi \%12 ve lisans eğitimi \%17 oranındadır. Üniversite mezunu (lisans eğitimli) zanaatkârlar en fazla kuyumculuk zanaatındadır (\%36). Bunların büyük bir çoğunluğu baba mesleği olduğu için bu mesleği yaptığını ve sevdiğini belirtmiştir.

Meslekteki deneyimleri bakımından, zanaatkârların \%40'ının kırk yılı aşkın süredir mesleklerini sürdürdüğü görülmektedir. Özellikle terzilik, ayakkabıc1lık ve bakırc1l1kta bu oran daha yüksektir (G. 16). Bu da zanaatkârlığın meslekte uzmanlaşmayı gerektiren bir birikim ve sürece ihtiyaç duyduğunu göstermektedir.

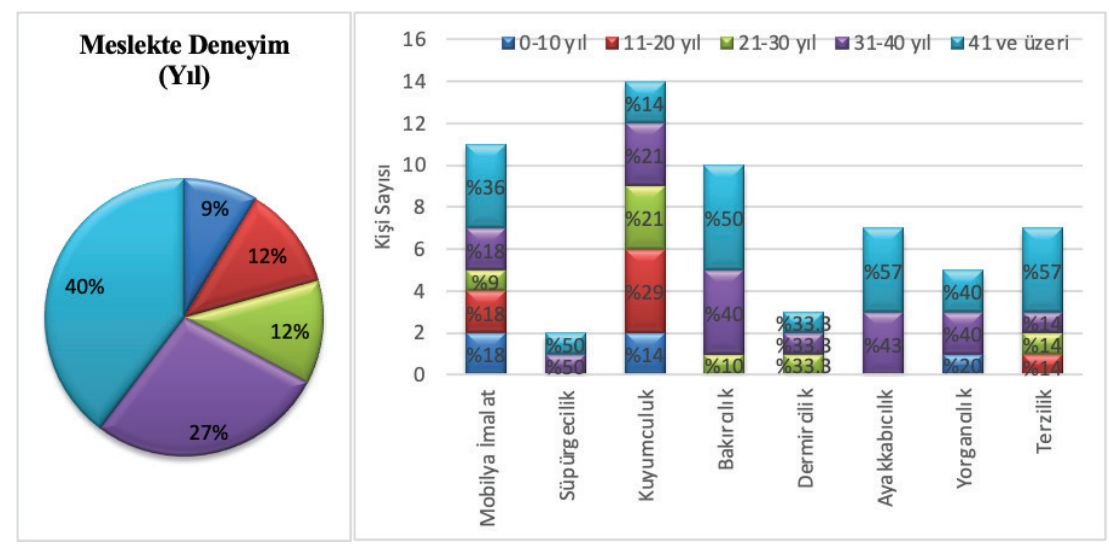

G. 16: Zanaatkârların Meslekteki Deneyim Süreleri (Nurçin Seymen, 2018)

Görüşmelerde zanaatkârlar; zanaat için genellikle benzer tanımlamalar yapmışlardır. Zanaatı çoğunlukla "el emeği ve el becerisiyle, sevgiyle yapılan meslek" olarak tanımlamışlardır. Ayrıca, "geçimini sağladiğı iş" olarak gören, "günümüzde kaybolmuş sanat", "altın bilezik" ve "sonu olmayan ve hiç tükenmeyecek bir iş" ş̧eklinde ifadeler de kullanmışlardır. Zanaatkârlara ne kadar süredir bulundukları mekânda oldukları da sorulmuştur. Yalnızca \%7'sinin 40 yıl ve daha fazla süredir aynı mekânda bulundukları görülmüştür. Bu zanaatlar; bakırcılık, demircilik, mobilya imalatçılığı (\%62) ve bakırcılık (\%60)'tır (G. 17). Bu durum göstermektedir ki zanaat mekânları geçmişteki konumlarına göre yer değiştirmiş, kapanmış ya da işlev değişikliğine gitmiştir. 


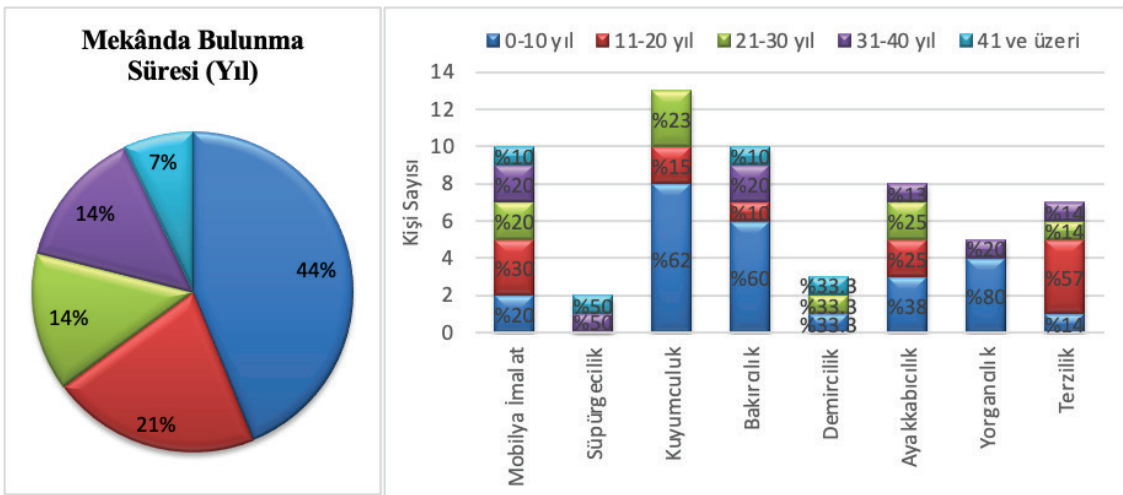

G. 17: Zanaatkârların Mekânda Bulunma Süreleri (Nurçin Seymen, 2018)

Zanaatkârların bulundukları mekânı tercih etme sebepleri arasında kent merkezinde olma (\%28) ve aynı zanaat türlerinin bir arada bulunması (\%25) öne çıkmaktadır. Bunun yanı sıra, ulaşım kolaylığı (\%9), babadan kalma bir yer olması (\%9), evine yakın olması (\%6) gibi sebepler de belirtilmişltir. Görüşülen zanaatkârların büyük çoğunluğu (\%86) zanaat mekânlarının bir arada bulunmasının gerektiğini vurgulamaktadır. Bir arada bulunmayı en önemli gören zanaat dalları, terzilik ( $\% 44)$, kuyumculuk (\%36) ve bakırcılık (\%28)’tır. Müşterilere alışverişte kolaylık sağlaması, zanaatkârlar arasında yardımlaşma ve birlik duygusunun güçlenmesi ve rekabet ortamı oluşması bakımından bir arada olmayı önemli görmektedirler (G. 18).

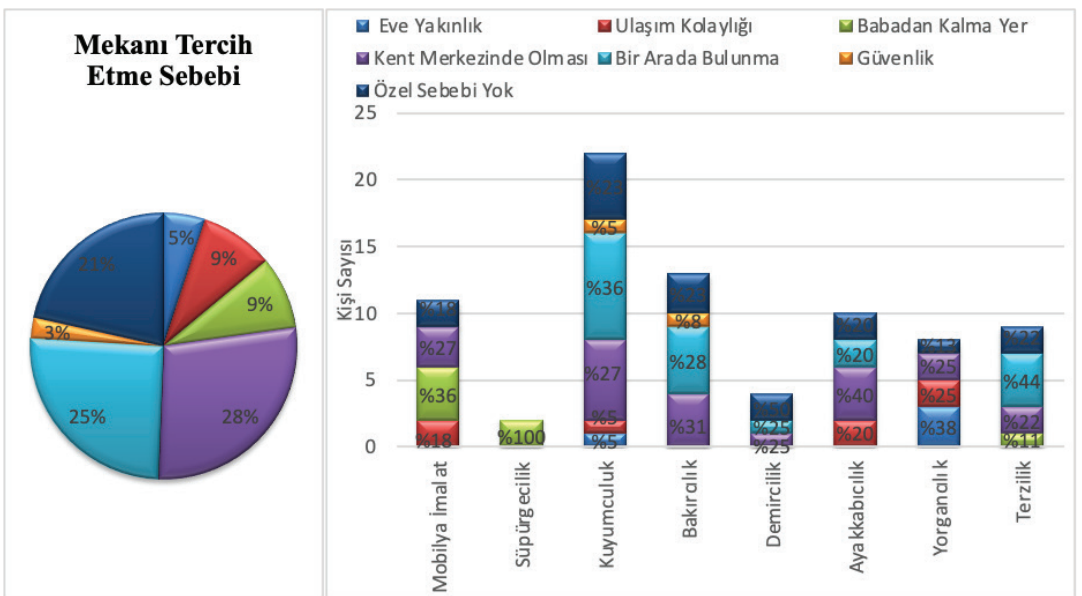

G. 18: Zanaatkârların Bulundukları Mekânı Tercih Etme Nedenleri (Nurçin Seymen, 2018)

Zanaatkârların sorunları hakkında da görüşleri alınmıştır. Zanaatkârların en önemli gördükleri sorunlar; zanaatkârların sayıca azalması (\%18), değişen tüketim alışkanlıklarına bağlı olarak müşteri talebinin azalması (\%16), iş yeri kiralarının yüksek olması (\%15), nitelikli eleman yetişmemesi (\%13), müşterinin alım gücünün düşmesi (\%13), zanaatla ilgili eğitimin eksikliği (\%11), mekânda yalnızlık (\%8) ve teknolojinin ge- 
lişmesi (\%6) olarak belirtilmiştir (G. 19). Zanaatkâr tarafindan belirtilen bu sorunların hepsi, el emeğiyle üretime verilen değerin azalması konusuna odaklanmaktadır. Önemli bir kültürel mirasın yok olduğunu da vurgulamaktadırlar.

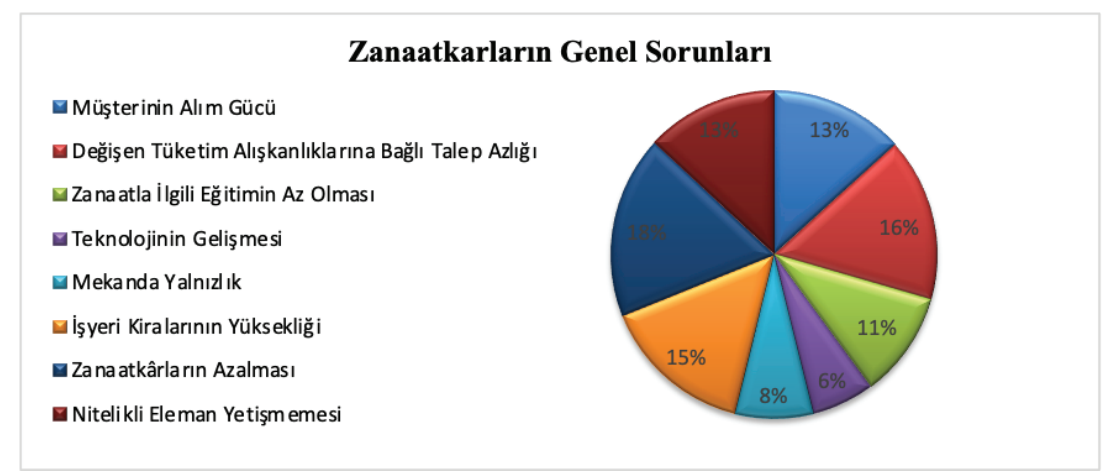

G. 19: Zanaatkârların Genel Sorunları (Nurçin Seymen, 2018)

Kentlerin tarihi ve kültürel yapısında önemli bir değere sahip olan zanaat mekânları genellikle tarihî çevrelerle iç içedir ve bu mekânlarla anlam bulmaktadır. Görüşülen zanaatkârların büyük bir çoğunluğu da (\%97'si) zanaatların bulundukları mekânlarla anlam bulduğunu, bu mekânların kentin kalbi olduğunu, korunup geliştirilmesi gerektiğini vurgulamışlardır. Ayrıca, zanaatkârların \%57'si zanaat mekânlarının tarihî mekânlarla ilişkili olması gerektiği konusunda görüş bildirmişlerdir.

Zanaatkârların \%71'inin bulundukları çevreden memnun olduğu, \%29'unun ise memnun olmadığ 1 tespit edilmiştir (G. 20). Memnun olmadıkları durumlar ise; belediye hizmetlerinin yetersizliği (\%54), sosyal olanakların kötü oluşu (\%14), tarihî değerlere önem verilmemesi (\%14), güvenlik sorunları (\%9) ve ulaşım zorlukları (\%9) olarak tespit edilmiştir. Özellikle kent merkezi dışında yer alan mobilyacılar sitesindeki mobilya imalatçıları belediye hizmetlerinin yetersizliğinden ve ulaşım sorunundan şikâyetçidir (\%33) (G. 21).

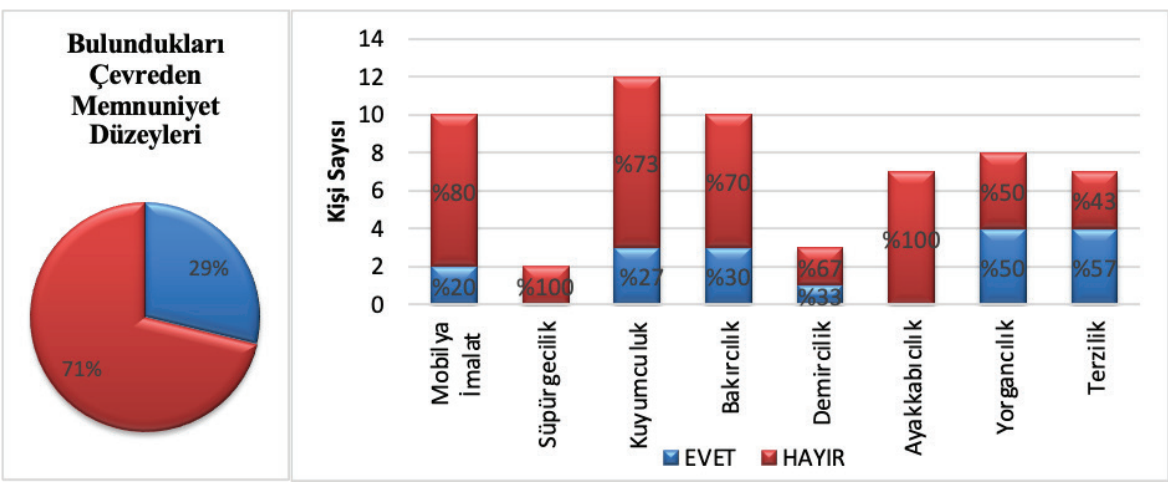

G. 20: Zanaatkârların Bulundukları Çevreden Memnuniyet Düzeyleri (Nurçin Seymen, 2018) 


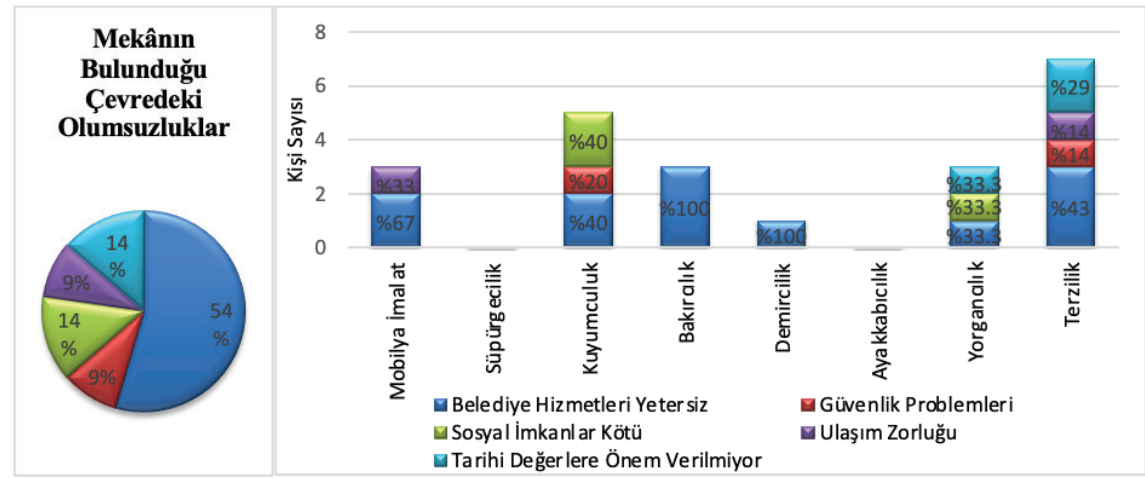

G. 21: Zanaatkârların Bulundukları Çevreden Memnun Olmadıkları Hususlar (Nurçin Seymen, 2018)

Zanaatkârlar istedikleri çevre hakkındaki görüşlerini; zanaatkârların bir arada ve birlik içinde olması (\%43), daha iyi komşuluk ilişkileri (\%23), geçmişin korunduğu mekân (\%19), daha eğitimli bir toplum (\%11), daha temiz bir çevre $(\% 5)$, daha sakin bir mekân (\%5), daha huzurlu bir çevre (\%3) ve daha bol yeşil alan (\%3) olarak belirtmişlerdir (G. 22).

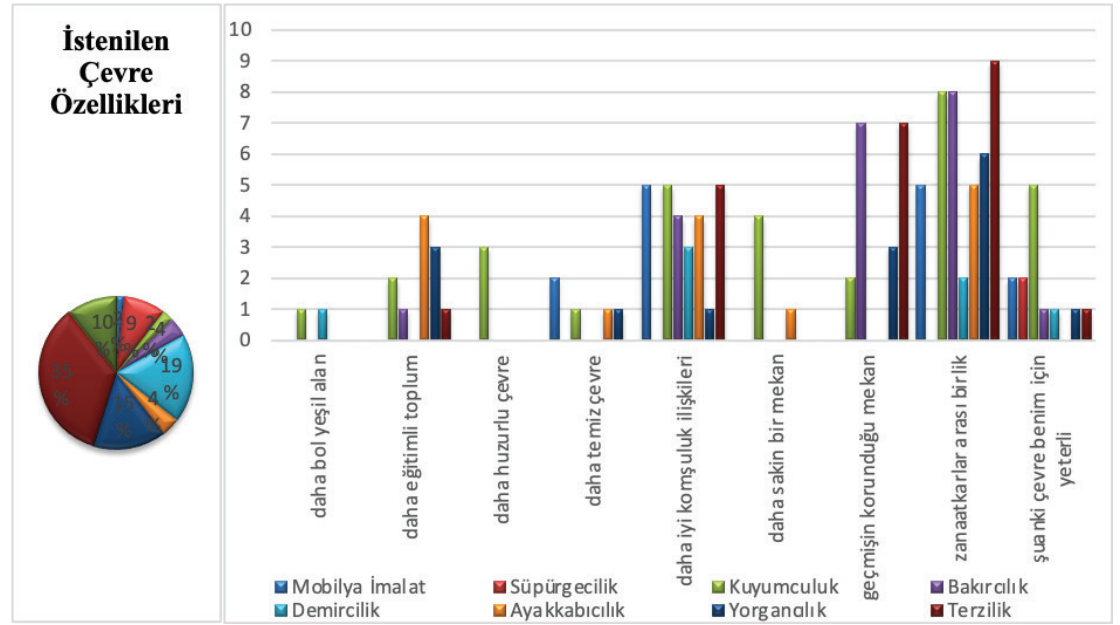

G. 22: Zanaatkârların Bulunmak İstedikleri Çevre Özellikleri (Nurçin Seymen, 2018)

Zanaatkârların, meslekleri ile ilgili olumsuz durumlara yönelik neler yapılabileceği konusunda da görüşleri alınmıştır. Mobilya imalatçıları teknolojinin el emeği üretimi bitirdiğini düşünmekte ve çıraklık eğitiminin mobilya ustalarının yanında verilmesi gerektiğini de vurgulamaktadırlar. Süpürgeciler ise kendi zanaatlarının artık gelişebileceğini düşünmemektedirler. Ayakkabıcılar, yeni modellerin üretilerek tüketicinin ilgisinin çekilebileceğini vurgulamaktadır. Ayrıca çırak yetiştirilmesi ve imalatçılara devlet desteği sağlanmasının da bu zanaatın sürekliliğinde önemli olduğunu söyle- 
mektedirler. Terziler ise, eğitim sisteminin zanaata yönelik değişmesini ve sanat okullarında zanaatla ilgili meslek derslerinin verilmesini vurgulamıştır. Yorgancılar da; nitelikli eleman yetiştirebilmek için eğitimin önemine vurgu yapmaktadır. Kuyumcular, meslekle ilgili eğitim veren merkezlerin artmasını, okullarda ders olarak okutulmasını, bu zanaatla uğraşanlar için özel bir mekân oluşturulmasını, atölye sayısının ve bunun için devlet teşviklerin artırılmasını, kuyumculuk zanaatını çekici kılacak projeler geliştirilmesi gerektiğini belirtmişlerdir. Bakırcılar ise hazır üretimin (Gaziantep ve Kahramanmaraş’tan gelen hazır bakır ürünler) Trabzon'daki bakırcılığı bitirdiğini, bu zanaat için devlet desteğinin yeterli olmadığını belirtmektedirler. Bakırcılığın gelişebilmesi için çırak yetiştiren okulların olması, imalatçıların üretime yönelik teşvik edilmesi ve desteklenmesi gerektiğini, kentte belgeli usta sayısının artmasını ve bakırcıların bir arada olabileceği bir mekânın olması gerektiğini vurgulamaktadırlar.

\section{Sonuç}

Günümüzde küreselleşmenin etkisiyle nüfus, ticaret ve tüketim hızı sürekli olarak artmaktadır. Bu artış kentlerin kimlik ve kültüründe önemli paya sahip geleneksel üretimlerin ve mekânların değişimlere sebep olmaktadır. Kentlerde ortaya çıkan bu değişimler çoğunlukla zanaat mekânlarının yoğunlaştığı tarihî kent merkezlerinde görülmektedir. Burada yer alan zanaat mekânları ise giderek azalmakta ve kaybolmaktadır. Değişimin getirdiği bu azalış ve yok oluş gelecekte zanaatların sürdürülebilirliği açısından önemli bir sorun teşkil etmektedir. Bu sebeple zanaat mekânlarının kimlik ve kültür bileşeni olarak ele alınması, korunması ve sürdürülebilmesi için planlama yaklaşımlarının geliştirilmesi önemlidir.

Araştırmada çalışma alanı olarak geçmişte ve günümüzde zanaat mekânlarına ev sahipliği yapan Trabzon tarihî kent merkezi seçilmiştir. Yerinde yapılan tespitler ve zanaatkârlarla görüşmeler sonucunda; sandıkç111k, sepetçilik, süpürgecilik, çömlekçilik ve dericilik zanaatlarının tamamen kaybolduğu, ayakkabıcılık, bakırcılık, yorgancılık ve terzilik zanaatlarının azalarak devam ettiği, kuyumculuk ve mobilya imalat zanaatlarının da sayıca arttığı görülmektedir.

Kentte kaybolan zanaatlar (sandıkçılık, sepetçilik, süpürgecilik, çömlekçilik ve dericilik) gelişen teknolojiye ayak uyduramamış ve insanların hazır üretime yönelmesi sonucunda varlığını koruyamamıştır. Kaybolan bu zanaat dallarıyla uğraşan zanaatkârlar ya yakın dallardaki işlere yönelmiş ya da tamamen zanaatkârlığı bırakmışlardır. Geçmişten günümüze azalarak devam eden zanaatlar ise (ayakkabıcılık, bakırc1lık, yorganc1lık ve terzilik) geçmişte bir arada bulunurken, günümüzde mekânsal olarak yer değiştirmiş, kentin farklı bölgelerine dağılmış ve sayıları giderek azalmıştır. Mobilya imalat ve kuyumculuk zanaatlarında ise daha önce de belirtildiği gibi artış olmuştur. 
Zanaat ve zanaat mekânlarına yönelik mekânsal ve sosyal bağlamda sorunlar ve potansiyeller değerlendirildiğinde dezavantajlı grupların çalışma alanına erişim zorluğu (Özellikle Kemeraltı Bölgesi), özgün değerlerin kaybolması, zanaat mekânlarının azalması, çalışma alanında okunabilirliğin zayıf olması, güvenlik düzeyinin düşük olması (özellikle Kemeraltı Bölgesi), zanaat eğitiminin yetersiz olması, nitelikli eleman yetiştirilememesi, zanaatkârların azalması, teknolojik ürünlerin geleneksel üretimin önüne geçmesi, zanaat ve zanaat mekânlarıyla ilgili arşiv eksikliği ve basın-yayın organlarında yeterli alanın zanaata ayrılmaması gibi sorunlarla karşı karşıya oldukları görülmektedir. Buna karşılık çalışma alanı tarihî kent merkezinde yer almaktadır. Bu alanda zanaatkârların bir arada bulunması, geleneksel tarihî dokunun kısmen korunmuş olması, alana erişilebilirliğin güçlü olması, alanın sosyal ve mekânsal olarak kent kültürünü yansıtan değerlere sahip olması, alandaki zanaat ve zanaat mekânlarının kültür mirası olarak kabul edilmesi için önemli potansiyellerdir.

Sonuç olarak alana ait sorun ve potansiyeller değerlendirildiğinde zanaat mekânlarının korunması, canlandırılması ve günümüzde taşıdığı izlerin sürdürülebilirliğinin sağlanması amacıyla planlama çalışmaları yapılması ve bu çalışmaların kamu, özel, STK ve halk iş birliğiyle zanaat odaklı kentsel politikalar geliştirilerek desteklenmesi oldukça önemlidir. Kentsel mekân ve zanaat kimliği oluşumunda önemli paya ait sokak ve meydanlar kullanılarak sergi, araştırma ve eğitim gibi etkinliklerin düzenlenebileceği zanaat odaklı kültür mekânları oluşturulması zanaat mekânlarının sürdürülebilirliğinin sağlanmasına yardımcı olacaktır.

Hakem Değerlendirmesi: Dış bağımsız.

Çıkar Çatışması: Yazarlar çıkar çatışması bildirmemiştir.

Finansal Destek: Yazarlar bu çalışma için finansal destek almadığını beyan etmiştir.

Peer-review: Externally peer-reviewed.

Conflict of Interest: The authors have no conflict of interest to declare.

Grant Support: The authors declared that this study has received no financial support.

\section{Kaynakça/References}

Aydın, Yelda. "Kentsel Gelişme ve Kent Merkezlerinin Dönüşümü: Trabzon Örneği.” Yüksek lisans tezi, Karadeniz Teknik Üniversitesi, 2001.

Aygün, Necmettin. Onsekizinci Yüzyılda Trabzon'da Ticaret. Trabzon: Serander Yayıncılık, 2005.

Belli, Oktay ve Gündağ Kayaoğlu. Trabzon'da Bakırcılık Sanatının Tarihsel Gelişimi. İstanbul: Arkeoloji ve Sanat Yayınları, 2002.

Durucu, Nuri. “Trabzon Kuyumculuğu.” Uluslararası Karadeniz Havzası Halk Bilimi Araştırmaları Dergisi 1 (2015): 112-181.

Doğan, Elif Tuğba. "Kitap İncelemesi: Richard Sennett: Zanaatkâr.” Ankara Üniversitesi Sosyal Bilimler Fakültesi Dergisi 65 (2010): 299-306. 
Öksüz, Melek. 18.Yüzyılda İkinci Yarısında Trabzon: Toplum-Kültür-Ekonomi. Trabzon: Serander Yayıncilik, 2006.

Ökten, Ayşe Nur ve Yiğit Evren. "İstanbul'da Geleneksel Kuyumculuk Sektöründe Yıkımın Coğrafyası: Zanaatkâr Gözüyle Mekân ve Yer.” 4. Kentsel ve Bölgesel Araştırmalar Sempozyumu Bildiri Kitabı. Mersin: Kentsel Bölgesel Araştırmalar Merkezi Yayınları, 2013, 652-660.

Ökten, Ayşe Nur ve Yiğit Evren. “Somut Olmayan Kültür Mirasının Sürdürülmesi İçin Üç Sektörlü Bir Model: İstanbul Tarihi Kent Merkezi İçin Kuyumculuk Mahallesi Önerisi.” Planlama Dergisi 23 (2013): 35-44.

Seymen, Nurçin. "Geçmişten Günümüze Zanaat ve Zanaat Mekânlarındaki Değişim: Trabzon Kenti Örneği." Yüksek lisans tezi, Karadeniz Teknik Üniversitesi, 2018.

Sümerkan, Mustafa Reşat. Trabzon Yöresi Geleneksel El Sanatları. Trabzon: Serander Yayıncılık, 2008.

Şahin, Fatih. "Alışveriş Merkezlerinin Biçimlenmesinde Önemli Boyutlardan Kamusal Mekân ve Kamusallık Olgusu.” Yüksek lisans tezi, Karadeniz Teknik Üniversitesi, 2005.

Şatır, Seçil. "Sürdürülebilirlik Temelinde Zanaat Üretimi ve Gelecekteki Önemi.” 15. Üretim Araştırmaları Sempozyumu Bildiri Kitabı. İzmir: Nobel Akademik Yayıncılık, 2015, 811-819.

Taşkın, Murat. “Trabzon'da Ticaret.” Trabzon. Trabzon: Eser Ofset Matbaacılık, 2013, 14-25.

Turan, Gülname. "Türkiye'de Erken Cumhuriyet Dönemi Zanaat ve Endüstri Üretiminde Tasarım.” Doktora tezi, İstanbul Teknik Üniversitesi, 2009.

Yalçın, Bilal. "Nasıl Zanaat ve Halk Sanatları Şehri Olunur." Uluslararası Türk Dünyası Turizm Araştırmaları Dergisi 1 (2016): 22-31.

“Trabzon Tabakhane Köprüsü”. Erişim 20 Ocak 2021. http://www.eskiturkiye.net/3275/trabzontabakhane-koprusu-1922

“Zağnos vadisi, Bedesten ve İpekyolu”, Erişim 05 Mart 2020. http://www.sanalbasin.com/zagnosvadisi-bedesten-ve-ipekyolu-17106647/ 
